\title{
Effects of dual tasks and dual-task training on postural stability: a systematic review and meta-analysis
}

REVIEW

This article was published in the following Dove Press journal:

Clinical Interventions in Aging

23 March 2017

Number of times this article has been viewed

\author{
Shashank Ghai ${ }^{1,2}$ \\ Ishan Ghai ${ }^{3}$ \\ Alfred $O$ Effenberg' \\ 'Institute of Sports Science, Leibniz \\ University, Hannover, Germany; \\ ${ }^{2}$ Department of Sports Science, \\ University of Waikato, Hamilton, \\ New Zealand; ${ }^{3}$ School of \\ Engineering \& Life Sciences, Jacobs \\ University, Bremen, Germany
}

\begin{abstract}
The use of dual-task training paradigm to enhance postural stability in patients with balance impairments is an emerging area of interest. The differential effects of dual tasks and dual-task training on postural stability still remain unclear. A systematic review and meta-analysis were conducted to analyze the effects of dual task and training application on static and dynamic postural stability among various population groups. Systematic identification of published literature was performed adhering to Preferred Reporting Items for Systematic Reviews and Meta-analysis (PRISMA) guidelines, from inception until June 2016, on the online databases Scopus, PEDro, MEDLINE, EMBASE, and SportDiscus. Experimental studies analyzing the effects of dual task and dual-task training on postural stability were extracted, critically appraised using PEDro scale, and then summarized according to modified PEDro level of evidence. Of 1,284 records, 42 studies involving 1,480 participants met the review's inclusion criteria. Of the studies evaluating the effects of dual-task training on postural stability, $87.5 \%$ of the studies reported significant enhancements, whereas $30 \%$ of the studies evaluating acute effects of dual tasks on posture reported significant enhancements, $50 \%$ reported significant decrements, and 20\% reported no effects. Meta-analysis of the pooled studies revealed moderate but significant enhancements of dual-task training in elderly participants (95\% CI: 1.16-2.10) and in patients suffering from chronic stroke ( -0.22 to 0.86$)$. The adverse effects of complexity of dual tasks on postural stability were also revealed among patients with multiple sclerosis ( -0.74 to 0.05$)$. The review also discusses the significance of verbalization in a dual-task setting for increasing cognitive-motor interference. Clinical implications are discussed with respect to practical applications in rehabilitation settings.
\end{abstract}

Keywords: multitasking, fall, balance, cognition, rehabilitation, training, coordination

\section{Introduction}

Postural stability is an integral component of the motor control and coordination process of the body, which is required for preserving steadiness during static and dynamic activities. ${ }^{1}$ This component relies upon proprioceptive afferents and complex sensorimotor actions. ${ }^{2-4}$ Posture is mediated by both higher "controlled" and lower "automatic" levels of processing, ${ }^{5,6}$ implying the involvement of basal ganglia-cortical loop for higher level processing ${ }^{7}$ and brainstem synergies for lower level processing. ${ }^{8}$ Studies have suggested that any alleviation in conscious-controlled attention toward postural control increases the likelihood of disrupting coordination and stability, 9,10 possibly, as a consequence of movement-specific reinvestment. ${ }^{9,11}$ The theory of reinvestment suggests that directing attention internally to control movement, which is usually automatic, can disrupt its performance..$^{9,10}$ The theory also suggests that 
aging $^{12}$ and neurological diseases ${ }^{9}$ are common conditions that increase reinvestment. Seidler et $\mathrm{al}^{13}$ reaffirmed these suggestions and associated physiological changes with aging and injury to loss in gray/white matter within the central nervous system, resulting in differential-reorganized cortical activation. Here, the authors suggested that differential cortical activation within the higher neural centers can affect task prioritization, further allowing increased conscious attention while carrying out cognitive or motor tasks. ${ }^{14}$

To resolve this issue, distracting dual tasks have been used in several studies. ${ }^{9,15-17}$ A dual task acutely directs the performer's attention toward an external source of attention (eg, n-back, random letter generation tasks), while performing a primary task. According to the constrained action hypothesis, this attentional change might allow motor systems to function in an automatic manner, resulting in more effective performance. ${ }^{10}$ Practical applications for enhancing the automation of postural control have been demonstrated in studies evaluating complex motor skills, ${ }^{18,19}$ postural stability, ${ }^{17}$ and gait. ${ }^{15}$

However, with an increase in complexity, a subsequent increase in cognitive processing and eventually cognitivemotor interference has been reported. ${ }^{20-23}$ This increase in central interference adversely affects both cognitive and motor performance. ${ }^{6,23}$ Studies speculate that inhibition of cognitive and balance ability post dual-task inclusion can be because of the bottleneck and central sharing model theories. $^{21,24}$ According to these theories, functioning of a neurological pathway mediating both cognitive and motor functions might be affected, when a continuous input as in a dual-task setting is directed with a primary task. This might adversely affect cognitive tasks or stability performance.

Similarly, a complexity-related decrease in cortical reciprocal inhibition in fall-prone population groups (elderly, patients with history of fall, with neurological diseases) has been identified as an important factor to promote postural instability. ${ }^{25,26}$ Studies suggest reduced gamma-aminobutyric acid B-mediated cortical inhibition ${ }^{27}$ and elevated muscular coactivation $^{26,28}$ to be the primary reasons for this effect. Boisgontier et al, ${ }^{6}$ Ruffieux et al, ${ }^{26}$ and Smith et $\mathrm{al}^{29}$ in their review studies concluded that application of dual task on fall-prone population groups results in postural instability and poor cognitive performance. However, minimal effects of cognitive-motor interference have been reported in a few reviews for diseased fall-prone population groups, which theoretically should exhibit poorer cognitive resources as compared to their healthy older counterparts. ${ }^{30,31}$ Therefore, there is a need to determine specific factors that in terms of complexity for a cognitive or motor task might result in differential effects on stability.

Furthermore, studies have extensively mentioned the beneficial effects of motor, ${ }^{32,33}$ dual-task training, ${ }^{34-36}$ for enhancing cognitive and motor performance even in fallprone population groups. Another important determinant that is commonly utilized to enhance stability and cognitive performance is physical exercise. ${ }^{32,33,37}$ The studies report these training maneuvers to be crucial for smoothening of various cognitive abilities and reducing cognitive-motor interference. ${ }^{38-40}$ Müller and Blischke ${ }^{41}$ suggested that the training allows modulation of consciousness-dependent motor activities to be more automatic, thereby reducing dual-task costs. Likewise, Bherer et $\mathrm{al}^{42}$ while reporting the beneficial effects in fall-prone population groups suggested freeing up of cognitive resources meant for monitoring performance to be the primary reason. The change in modulation of motor activity has been suggested to allow automatization by "structural displacement", ${ }^{43,44}$ where a shift in the operation control of motor planning and executive control occurs from higher cognitive centers to basic noncognitive centers. ${ }^{45,46}$ This training maneuver has recently drawn a lot of interest as compared to its older counterpart and speculations persist as to which protocol overlays beneficial effects on postural stability among different population groups..$^{47,48}$ Recent review studies evaluating the effects of dual-task training in elderly ${ }^{38,49}$ and population groups with neurological diseases ${ }^{50,51}$ conclusively report the beneficial effects of dual-task training for enhancing cognitive abilities and stability, whereas some review studies report no identifiable benefits. ${ }^{33,52}$ The studies also mentioned the increased heterogeneity of the training protocols within the studies to cause difficulties in identifying a specific method's effectiveness. Wang et al, ${ }^{51}$ for instance, in their meta-analysis reported benefits of dual-task training on static stability, however, with considerable heterogeneity $(I: 88 \%)$. This review was an attempt to extend the efforts of the previous reviews and comparatively examine the effects of dual tasks, dual-task training methodologies on the postural stability of healthy and fall-prone population groups. The review also aimed to conduct meta-analysis across homogeneous groups for determining effective methodologies in terms of complexity and training methodologies for dual task and dual-task training scenarios.

\section{Methods}

This review was conducted according to the guidelines outlined in Preferred Reporting Items for Systematic Reviews and Meta-analysis (PRISMA) statement. ${ }^{53}$ 


\section{Data sources and search strategy}

The databases Scopus, PEDro, SportDiscus, EMBASE, and MEDLINE were searched from inception until June 2016. The search was limited to the abovementioned databases due to access regulations of the university. Keywords for search strategy were included using medical subject headings (MeSH). An example of the search strategy for EMBASE database has been provided in Table S1. The inclusion criteria for the studies were as follows: 1) studies that were randomized controlled trials (RCTs), cluster RCTs, and controlled clinical trials (CCTs); 2) measurement of postural stability using highly valid and reliable methods (static and dynamic posturographic analyses, center of pressure, center of gravity analysis, sensory orientation test, Berg balance scale, time up and go test, star excursion balance test, modified star excursion balance test, and active movement extent discrimination apparatus); 3) dual tasks performed during the research were reliable and valid; 4) studies that scored $\geq 4$ on the PEDro methodological quality scale; 5) experiments that were conducted on human participants; 6) published in a peer-reviewed academic journal; and 7) articles that were published in English language. Studies evaluating the abovementioned parameters in participants below the age of 18 years were not included, as development of postural control centers has been reported to take place during this developmental phase. ${ }^{54}$ Studies were excluded if they analyzed postural stability in a sitting position or while using a picture analysis software. All the studies identified during the search were independently screened (Figure 1) for eligibility by a primary researcher and every effort was undertaken to avoid subjective bias. ${ }^{55}$ Preliminary analysis for selection was performed by analyzing titles and abstracts, and, wherever necessary, the entire text of the article was studied. Where further clarification of the published data was required, the

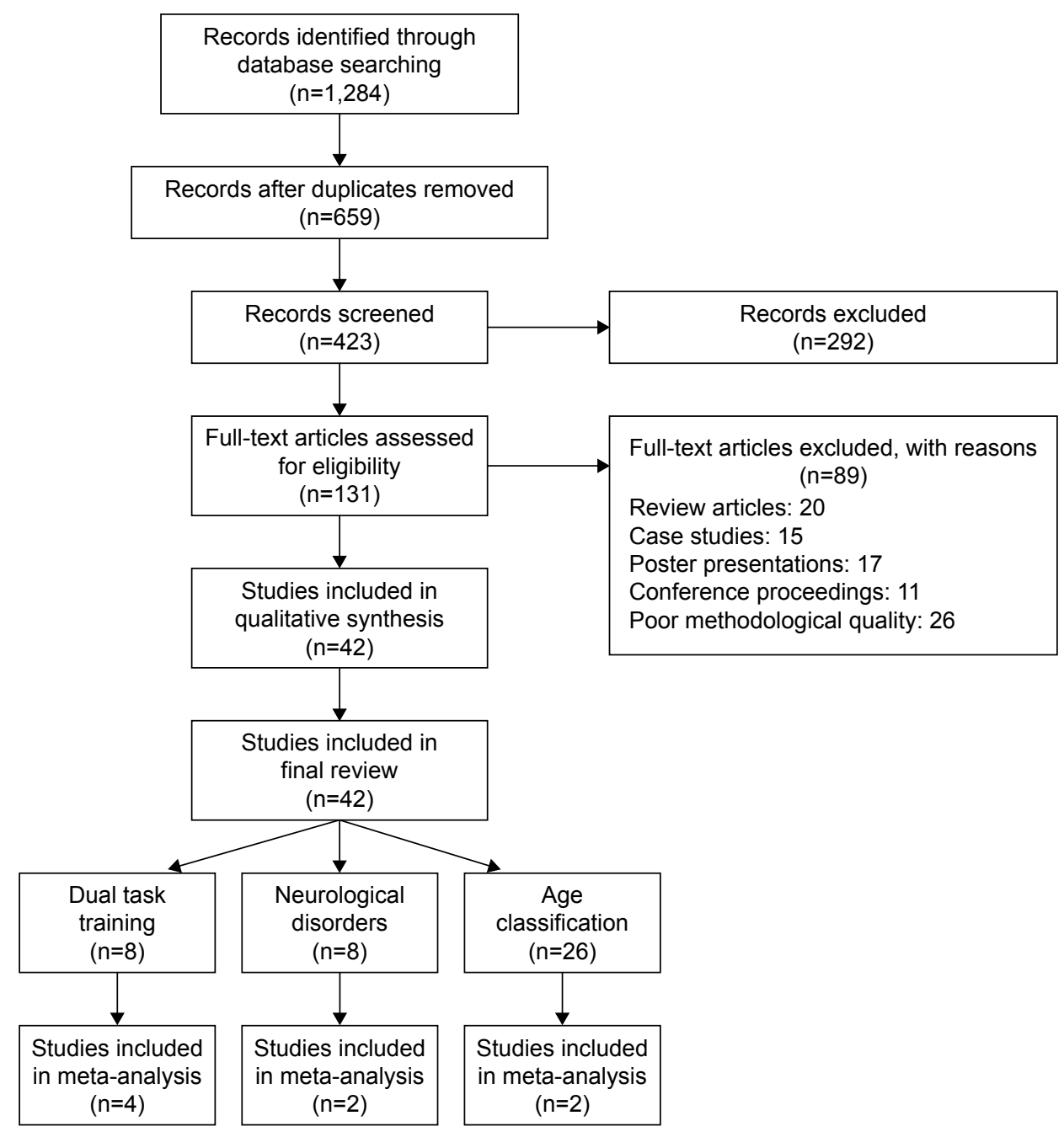

Figure I Flow diagram illustrating studies for inclusion in the review study (PRISMA flow diagram). Abbreviation: PRISMA, Preferred Reporting Items for Systematic Reviews and Meta-analysis. 
first researcher attempted to contact the respective authors. Bibliographic sections of all the articles were retrieved for evaluations. Citation search for all the included articles was performed using Web of Science. A classification of studies based on their experimental design ${ }^{56}$ and country of origin was also made (Supplementary material).

\section{Data extraction}

Upon selection for review, the following data were extracted from each article: author, date of publication, selection criteria, sample size, sample description (gender, age, health status), intervention, dual-task, outcome measures, results, and conclusions. The data were then summarized and tabulated. Furthermore, classification of studies was made based on their experimental application, ${ }^{56}$ and the population groups were assessed.

\section{Quality and risk of bias assessment}

The quality of the studies was assessed using the PEDro methodological quality scale. The scale consists of eleven items addressing external validity, internal validity, and interpretability. The PEDro scale can detect potential bias with fair to good reliability ${ }^{57}$ and is a valid measure of the methodological quality of trials. A blinded rating of the methodological quality of the studies was carried out by the primary reviewer. Ambiguous issues were discussed between reviewers, and consensus was reached. For the included CCTs, a scoring of 9-10, 6-8, and 4-5 was considered to be of "excellent", "good", and "fair" quality, ${ }^{58}$ respectively. Likewise, the level of evidence was suggested to be of level 1a (strong) if more than one RCT $(\geq 6), 1 \mathrm{~b}$ if one RCT $(\geq 6)$, and 2 if one RCT $(<6)$, or CCTs with similar methodological approaches were consistent with the results. ${ }^{58}$ With differential results among paired groups of studies, the result of the study(s) with higher PEDro score was given more consideration. Inadequate randomization, nonblinding of assessors, no intention to treat analysis, and no measurement of compliance were major threats to biasing. ${ }^{2}$

\section{Data analysis}

This systematic review also included a random-effect meta-analysis approach to develop a better understanding of the incorporated interventions. A narrative synthesis of the findings structured around the intervention, population characteristics, methodological quality (Table 1), and the type of outcome is provided. Likewise, summaries of intervention effects for each study were provided in a tabular form (Table S1). A meta-analysis was conducted between pooled studies using comprehensive meta-analysis (CMA V 3.0; Englewood, NJ, USA). Heterogeneity between the studies was assessed using $P^{2}$ statistics. The data in this review were systematically distributed and for each available variable pooled, dichotomous data were analyzed and forest plots with $95 \%$ confidence intervals (CIs) are reported. The effect sizes were adjusted and reported as Hedge's $g$. Thresholds for interpretation of effect sizes were as follows: a standard mean effect size of 0 means no change, negative effect size means a negative change, mean effect size of $<0.1$ is considered a small effect, $0.1-0.3$ a medium effect and $>0.30$ a large effect. ${ }^{59,60}$ Interpretation of heterogeneity via $I^{2}$ statistics was as follows: 0-40\% might not be significant, 30\%-60\% represents moderate heterogeneity, 50\%-90\% represents substantial heterogeneity, and 75\%-100\% represents considerable heterogeneity. Meta-analysis reports including heterogeneity among studies were evaluated to determine the reason of heterogeneity, and the included studies were then pooled separately and analyzed again. The alpha level was set at $95 \%$.

\section{Results}

\section{Characteristics of included studies}

The initial search yielded 1,284 studies, which on implementing the inclusion/exclusion criteria were reduced to 42 (Figure 1). Data from the included studies are summarized in Table 1. Of the 42 studies, three were RCTs, ${ }^{34-36}$ and 39 were CCTs. Eight studies evaluated the effects of dual-task training on postural stability. ${ }^{34-36,48,61-64}$ Eight studies evaluated the effects of dual tasks on participants suffering from neurological diseases, such as degenerative cerebellar disorder, Parkinson's disease, and multiple sclerosis. ${ }^{21,65,66}$ Twenty-six studies evaluated the effects of dual tasks on postural stability among healthy young and/or elderly participants. ${ }^{16,17,20,67-89}$ Within these 26 studies, 14 studies compared the effects between young and elderly participants, eleven studies evaluated only young and one study evaluated only elderly participants.

\section{Participants}

Of the included studies, 33 studies incorporated mixedgender participant groups. ${ }^{16-18,20-22,36,61-67,69-78,81-84,87,88,90-94}$ Four studies incorporated only female participants, ${ }^{35,79,85,86}$ and two studies incorporated only male participants. ${ }^{34,89}$ Three studies did not specify the gender of the included participants. ${ }^{48,61,80}$ The included studies provided data on 1,480 participants ( $\mathrm{n}=796$ females/581 males). Descriptive statistics related to the age (mean \pm standard deviation) of the participants were tabulated across the studies. Three studies 


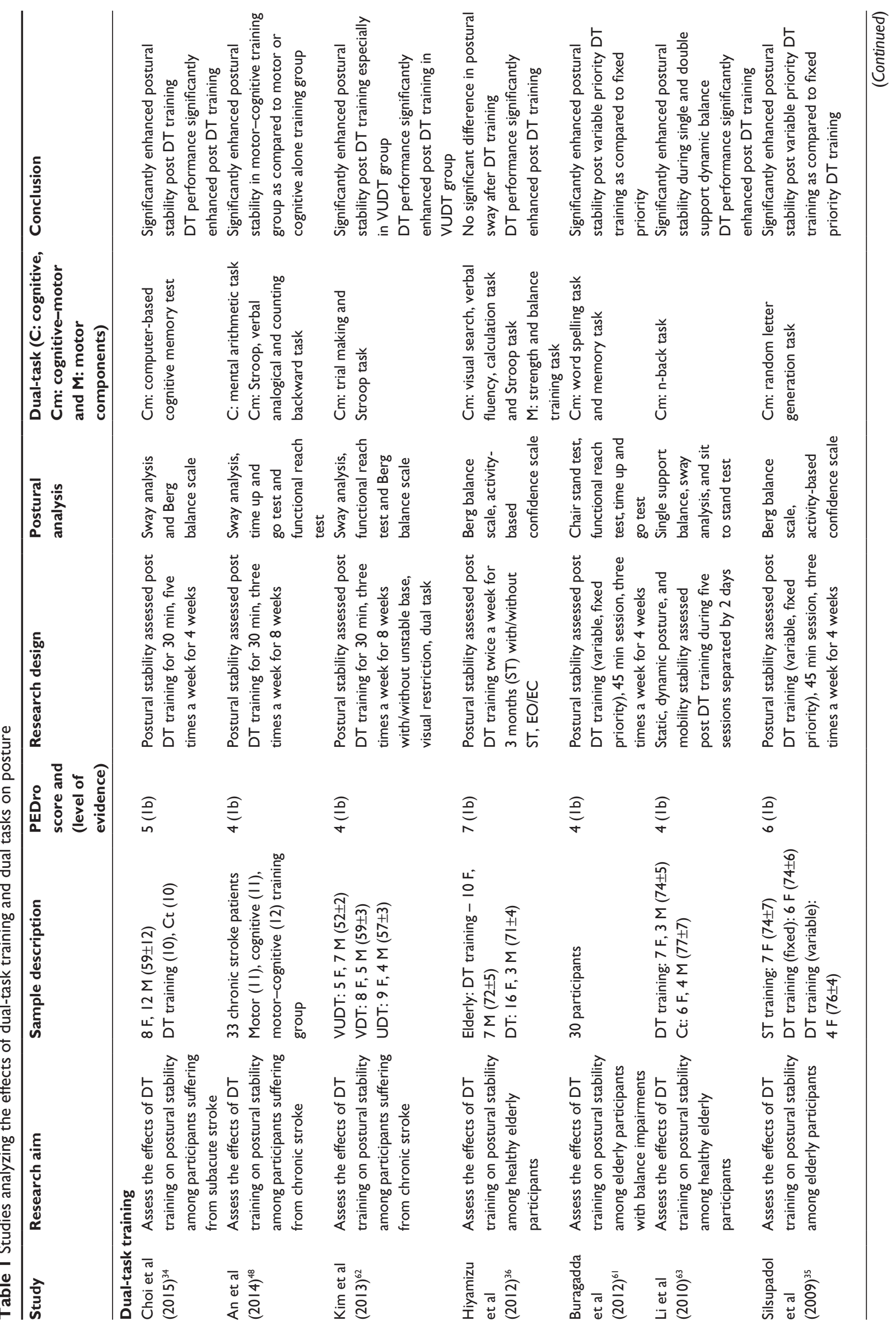




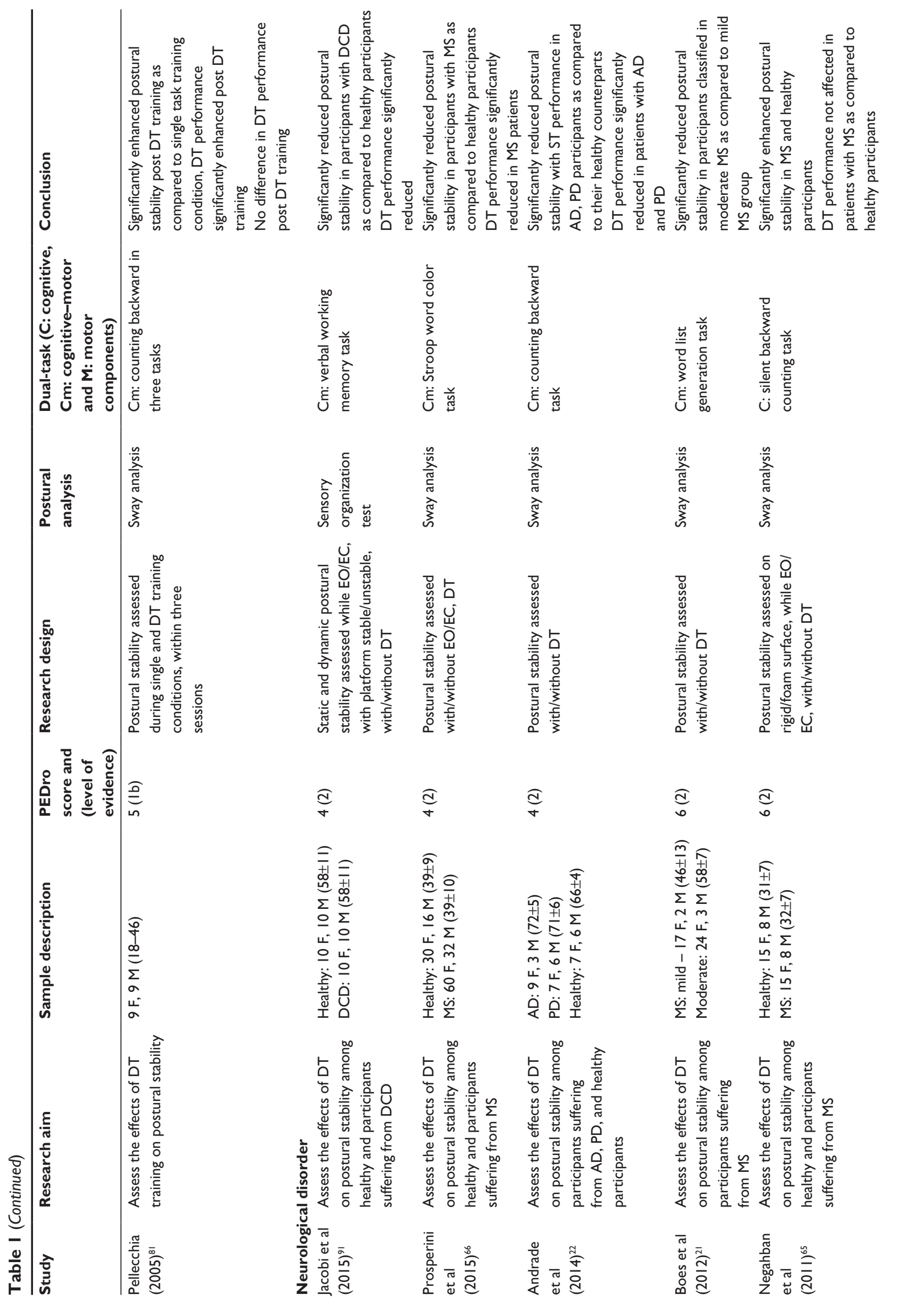



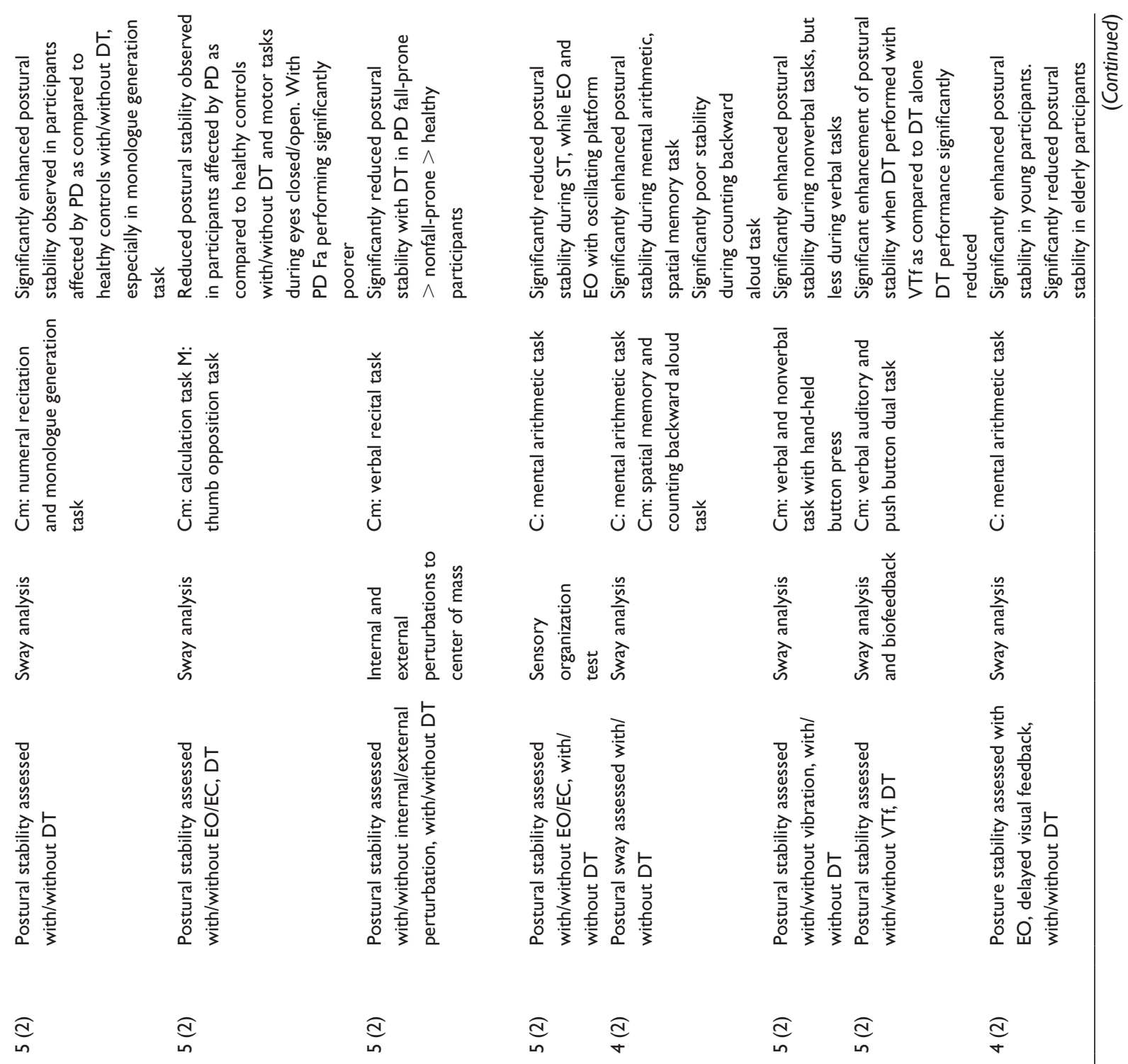

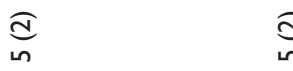

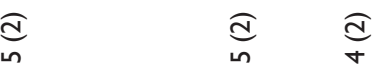

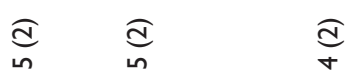

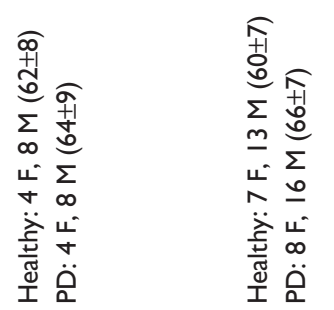

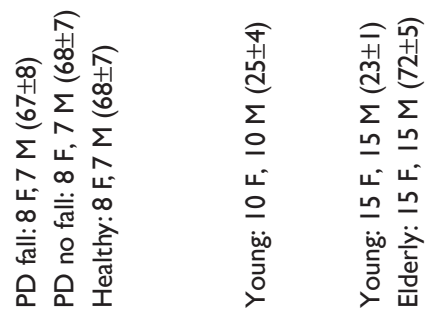

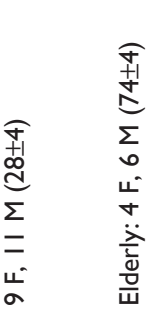

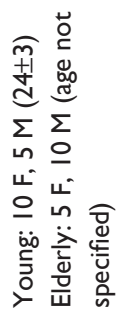

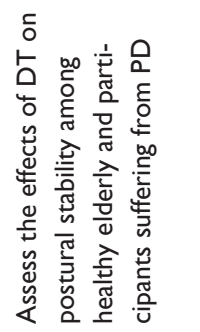

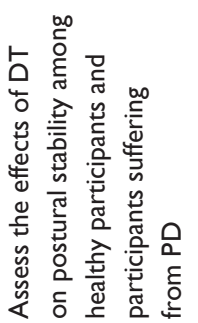

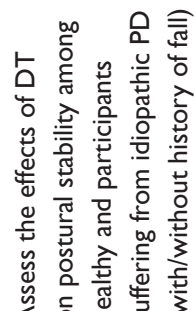

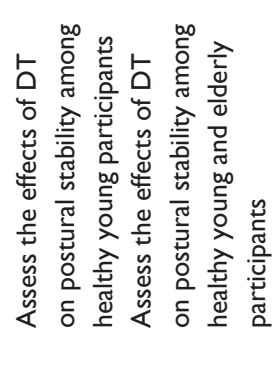

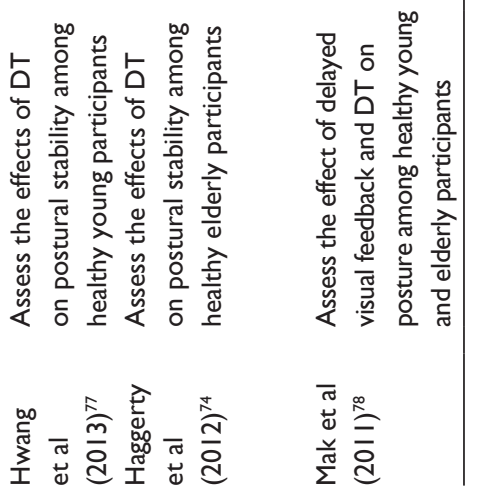

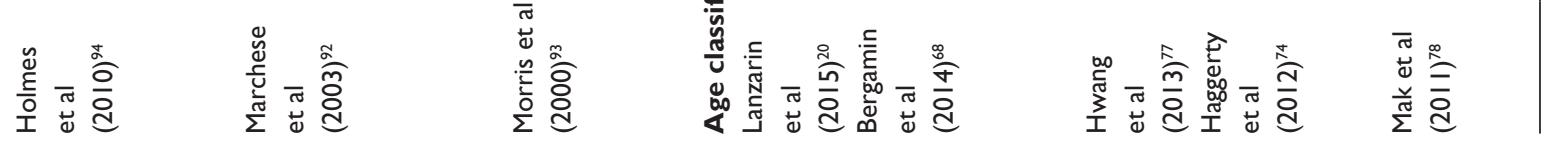




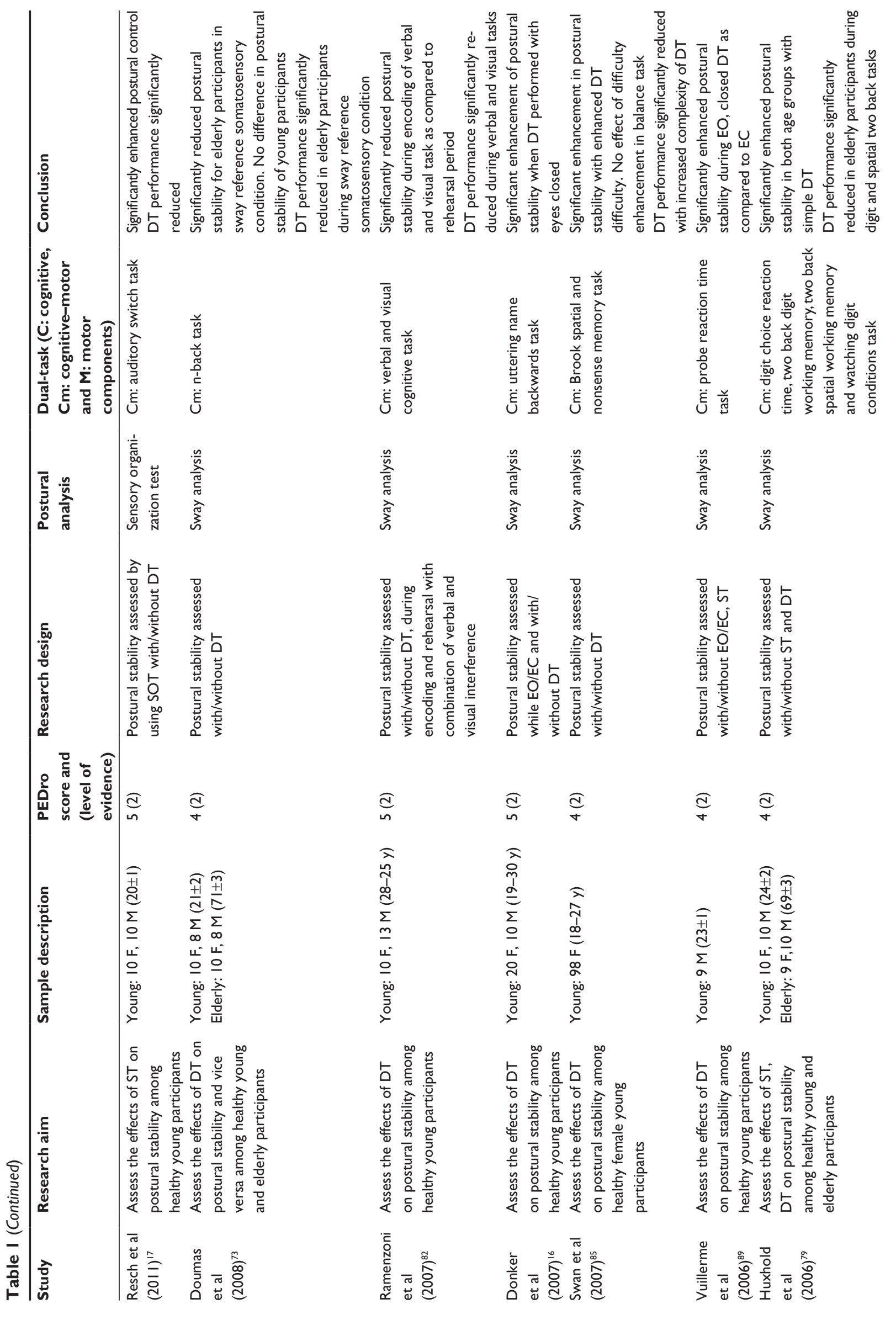



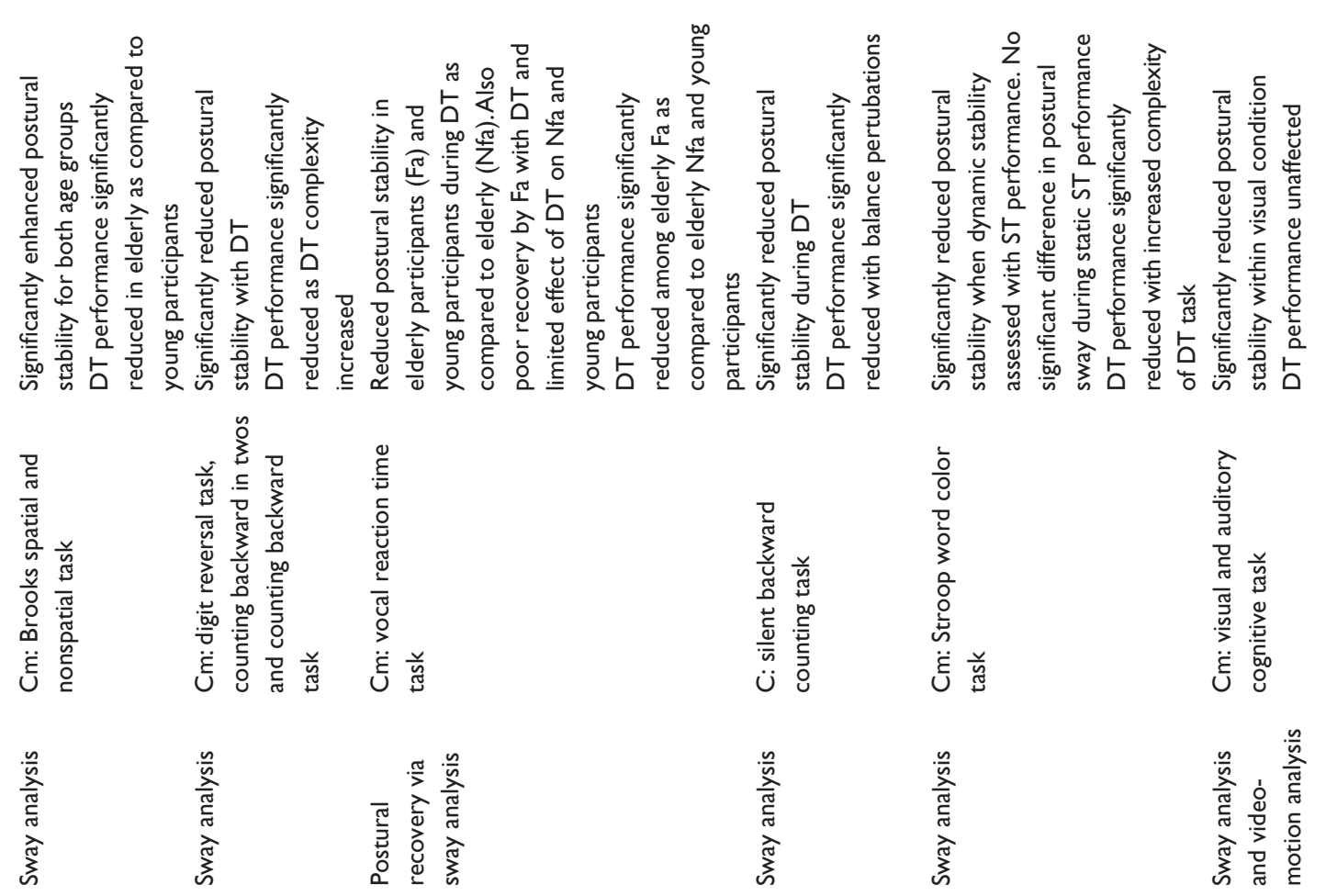

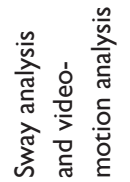
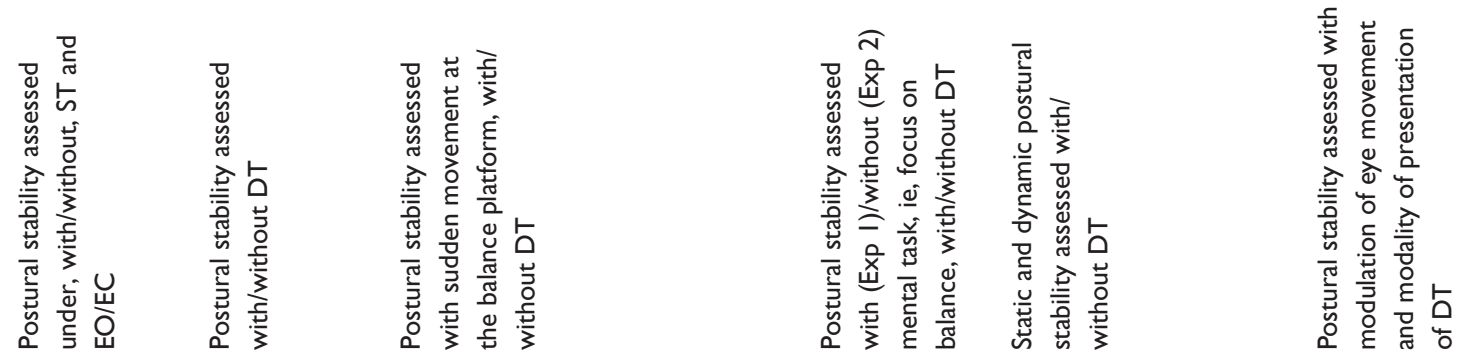

$\underset{n}{\sqrt{n}} \frac{a}{\sqrt{n}}$

$\frac{a}{3}$

ลก

$\underset{d}{a}$

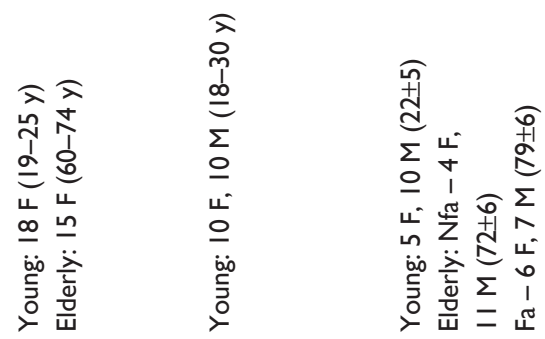

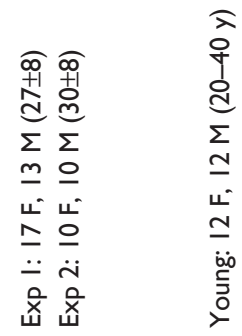

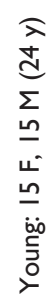

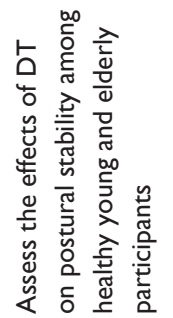

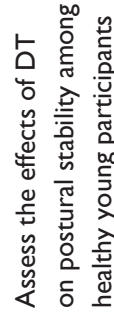

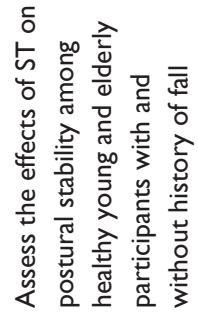

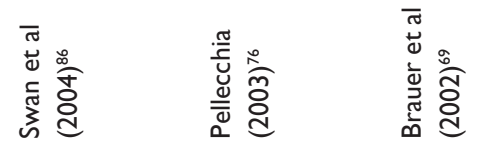

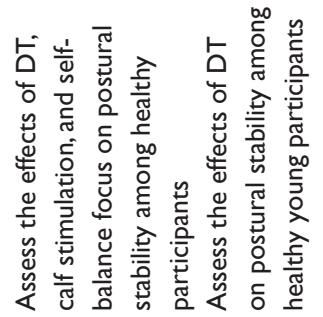

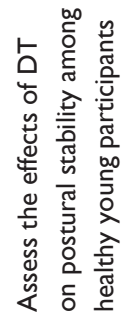

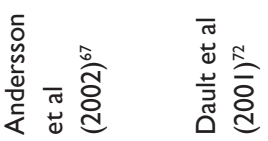

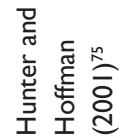




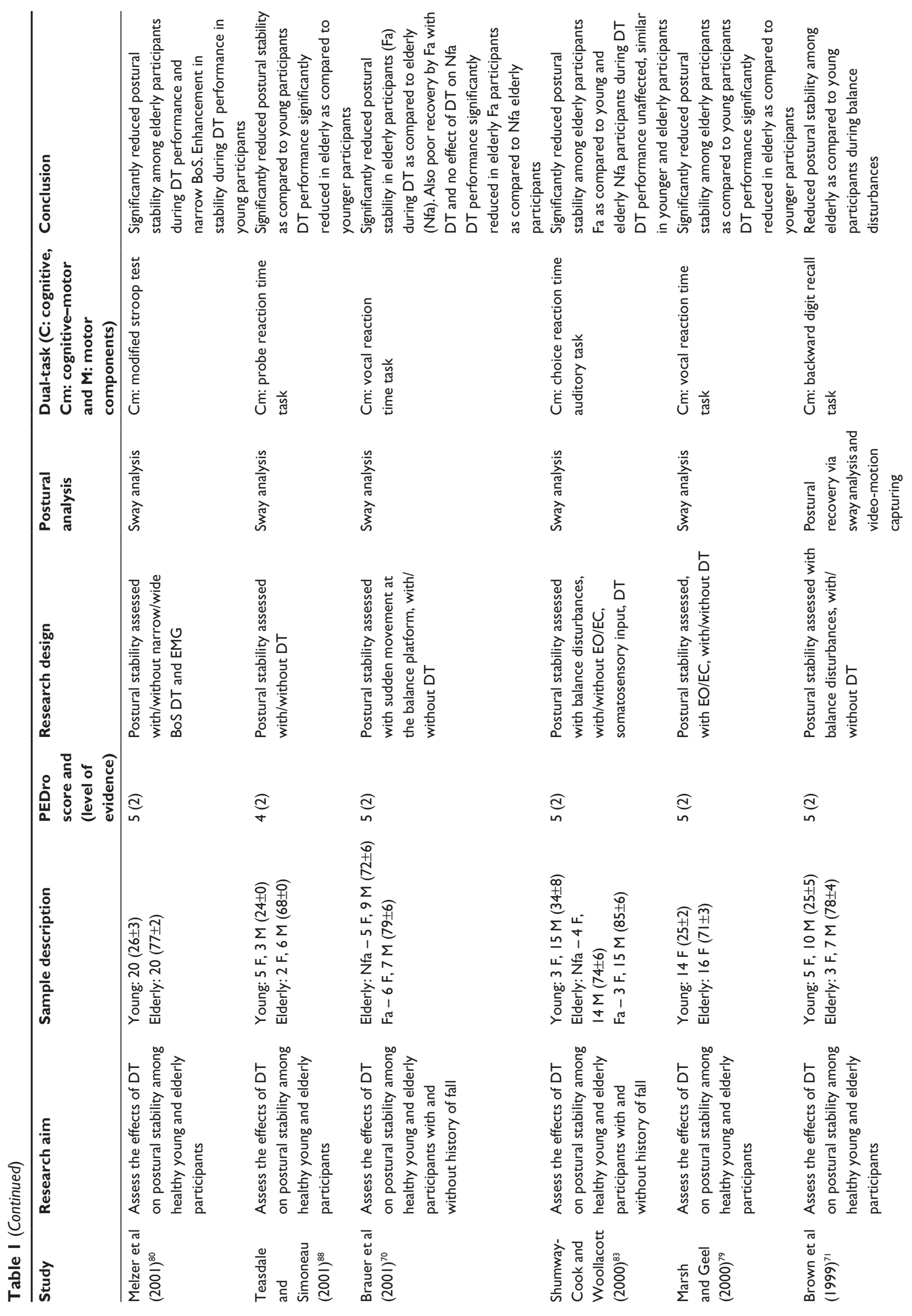



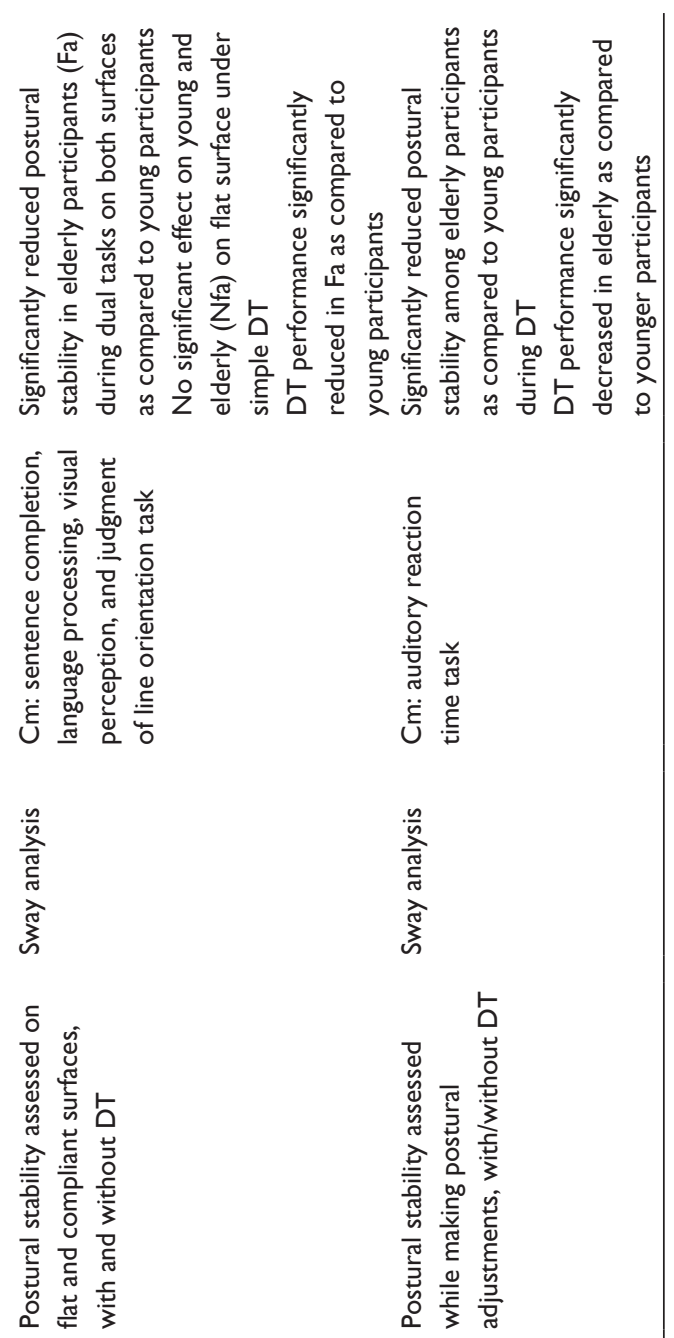

$\frac{\frac{n}{n}}{\frac{\pi}{\sqrt{0}}}$

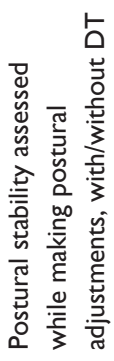

ลก

$\underset{d}{d}$

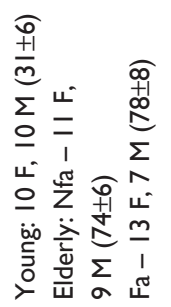

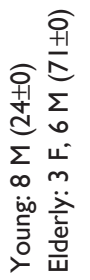
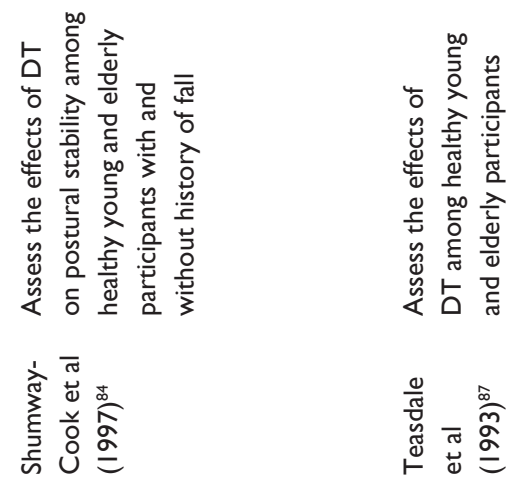

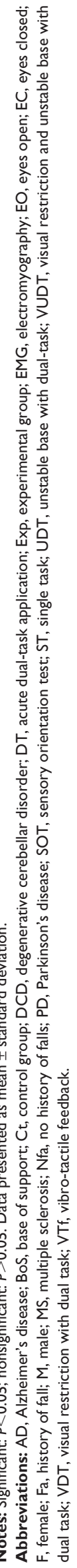

provided the median age of participants, ${ }^{75,87,88}$ and five studies mentioned the age of participants in range. ${ }^{16,81,82,85,86}$

\section{Risk of bias within studies}

In order to efficiently reduce the risks of bias, the studies had to score $\geq 4$ on PEDro scale to be included in the review. The criteria for research studies to be included in the review were limited to gold standard RCTs, cluster RCTs, and CCTs. The individual scores attained by the studies using the PEDro scale are reported in Tables 1 and $\underline{\mathrm{S} 2}$. The average PEDro score for the 42 included studies was computed to be 4.7 out of 10 , indicating fair quality of the overall studies. One study scored $7,{ }^{36}$ three studies scored $6,{ }^{21,35,65}$ 20 studies scored 5,,$^{16,17,20,34,69-72,74,77,79-84,86,92-95}$ and 18 studies scored $4.22,48,61-63,66-68,73,75,76,78,81,85,87-89,91$

\section{Risk of bias across studies}

Common methodological shortfalls observed in this review were inadequate concealment, intention-to-treat, nonblinding of participants, therapists, and assessors. One study reported blinding of assessors and confirmed intention-totreat the included participants. Furthermore, only two studies confirmed concealed allocation of subjects. ${ }^{35,36}$ The authors could not interpret concealed allocation of participants in three studies, ${ }^{65,82,85}$ and, therefore, no points were awarded to the studies. The overall risk of bias for quality assessment within studies is illustrated in Figure 2.

\section{Meta-analysis}

The evaluation of research studies via meta-analysis requires strict inclusion criteria to efficiently limit the heterogeneity. ${ }^{96}$ However, among the pooled group of studies the authors observed unexplained heterogeneity, suggesting incorporation of a random-effect meta-analysis under such conditions. The researchers added that a random-effect metaanalysis involves an assumption that the estimated effects in various studies are unidentical but follow some distribution. Therefore, studies analyzing similar variables were pooled, and a random-effect meta-analysis was conducted across four categories (dual-task training: elderly participants, dual task: multiple sclerosis, young, old). The main reason for not including the statistical approach within the studies was major differences in training duration, assessment methods, age/gender, complexity of dual tasks, and lack of descriptive statistics within the manuscript. The descriptive statistics mentioned within illustrative figures were not included in the study. The authors included ten studies in the meta-analysis which incorporated evaluation of postural 


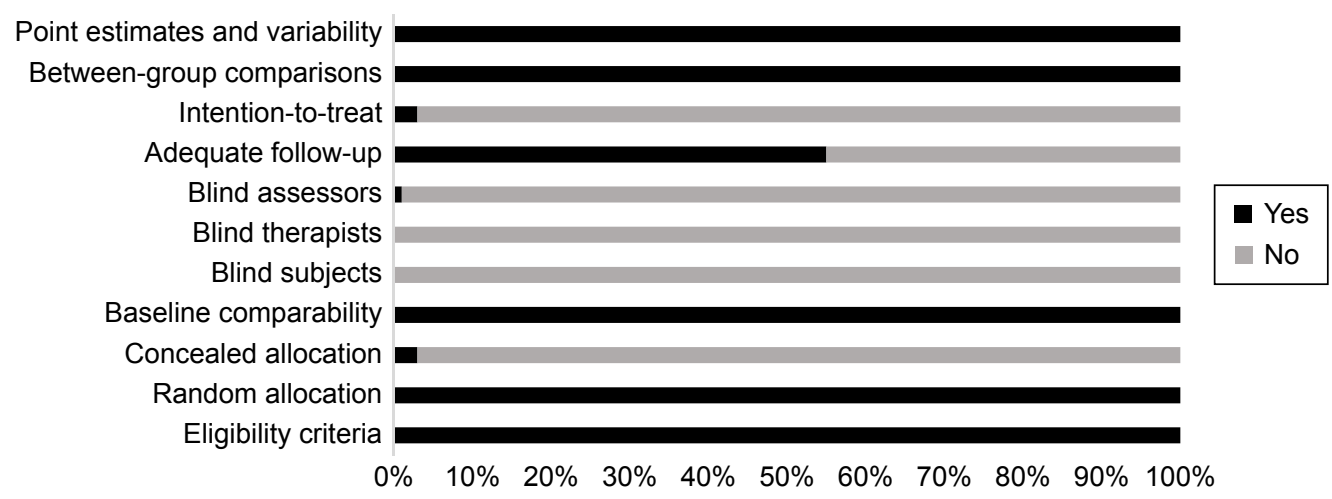

Figure 2 Risk of bias across studies.

stability in participants similar at baseline and were evaluated with similar methodological approaches, but with different dual tasks. The aim of such analysis was to demonstrate the differential effects of complexity of dual tasks on postural stability. Additionally, the reasons for specific studies are mentioned subsequently.

\section{Dual-task training}

Eight studies under this category analyzed the effects of dual-task training on postural stability, whereas four studies, in two different categories, were included in the metaanalysis. ${ }^{35,48,61,62}$ From the nonincluded studies, one study analyzed the effects of dual-task training on subacute stroke patients, ${ }^{34}$ two studies analyzed the effects on elderly participants, ${ }^{36,63}$ and one study on younger participants. ${ }^{64}$ The two studies analyzing the effects of dual-task training on elderly participants considerably differed based on training duration and incorporated dual tasks. Hiyamizu et $\mathrm{al}^{36}$ incorporated Stroop task with a dual-task training duration of two sessions per week for 3 months; however, Li et al ${ }^{63}$ used an n-back task with a training duration spread over five sessions with a 2-day gap within each session.

\section{Neurological impairment}

Eight studies under this category analyzed the effects of dual task on postural stability of participants affected by neurological disorders. Two studies analyzing the effects of dual task on multiple sclerosis were included in the metaanalysis. However, the third study despite having similar variables could not be included as the descriptive statistics were not available in the text and were not obtained even after contacting the corresponding author. Similarly, three other studies analyzing patients affected by Parkinson's disease could not be included due to lack of descriptive statistics. ${ }^{22,92,93}$ Only one study analyzed the effects of dual tasks on postural stability of participants affected from degenerative cerebellar disorder. ${ }^{91}$

\section{Young and elderly participants}

Twenty-six studies under this category analyzed the effects of dual task on young and/or elderly participants. Four studies analyzing the effects of dual task on young and elderly participants were included in the meta-analysis. ${ }^{17,20,80,94}$ Thirteen studies analyzing similar variables in terms of age and dual tasks were not included in the meta-analysis as they did not include descriptive statistics explicitly, but in figures, ie, bar diagrams. ${ }^{16,67,68,72,75,76,79,82,85-89}$ Shumway-Cook and Woollacott ${ }^{83}$ and Shumway-Cook et al ${ }^{84}$ evaluated the effects of dual task on postural stability during balance perturbations in participants predisposed to falls, their healthy counterparts, and young participants, while the studies differed in terms of utilized dual tasks. Mak et al, ${ }^{78}$ on the contrary, included a rather novel aspect of visual feedback during standing and utilized dual tasks in conjugation with this feedback approach. Hwang et $\mathrm{al}^{77}$ also utilized one leg standing as compared to the counterpart studies, which utilized a basic two-legged standing under different conditions. Brauer et al ${ }^{69,70}$ analyzed postural recovery post balance perturbation with dual tasks among participants predisposed to falls, their healthy counterparts, and young participants with similar dual tasks. Likewise, Brown et $\mathrm{al}^{71}$ also utilized a similar approach and effective comparisons could have been drawn between studies to evaluate the effects of dual task on postural stability. Due to lack of descriptive statistics, and not heterogeneity, the studies could not be included in the analysis.

\section{Outcomes}

The results suggest clear evidence for a positive impact of dual-task training for enhancing postural stability among fall-prone elderly population groups and participants affected 
from stroke. A negative impact of dual tasks was observed in studies evaluating the effects of dual tasks on postural stability among fall-prone population groups affected by neurological disorders and/or with prior history of fall, as compared to their younger healthier counterparts.

\section{Meta-analysis report Dual-task training}

Eight studies evaluated the effects of dual-task training on postural stability. ${ }^{34-36,48,61-64}$ One $\mathrm{RCT}^{34}$ and two CCTs evaluated the effects of dual-task training on postural stability in subacute and chronic stroke patients, respectively. Two RCTs ${ }^{35,36}$ and three CCTs evaluated the effects of dualtask training on elderly and young participants. Significant enhancements in postural stability were reported in one $\operatorname{good}^{35}$ and six fair-quality studies..$^{34,48,61-64}$ However, one good-quality study reported no significant enhancements in postural stability. A random-effect meta-analysis was conducted across two categories. First, two studies evaluated the effects of fixed and variable priority dual-task training on postural stability among elderly population groups. ${ }^{35,61} \mathrm{~A}$ random letter generation task was utilized during the training phase which lasted for a 45-min session, three times a week for 4 weeks. Scores from Berg balance scale were utilized to assess the postural stability. Upon analysis, a large effect size was observed (Hedge's g: 1.63), and 95\% CI (1.16-2.10) was reported in the positive domain, demonstrating a beneficial effect of variable task priority within dual-task training to enhance postural stability (Figure 3A). Heterogeneity tests reported negligible heterogeneity $\left(I^{2}: 20.26 \%, P<0.01\right)$. Moreover, the studies were then reevaluated on the basis of fixed and variable priority dual-task training. In the condition of fixed priority dual-task training, upon analysis, a large effect size was observed (Hedge's g: 1.42) and 95\% CI (0.79-2.05) in the positive domain. Similarly, in the condition of variable priority dual-task training, a large effect size was observed (Hedge's $g$ : 1.91) and 95\% CI (1.19-2.63) in the positive domain. Thereby, demonstrating a beneficial effect of variable priority over fixed priority dual-task training method.

Second, two studies analyzing the effects of dual-task training on postural stability among patients affected from chronic stroke were included in the meta-analysis. ${ }^{48,62}$ The studies utilized a similar dual-task training duration phase of a 30-min session, three times a week for 8 weeks. Postural stability in the studies was assessed using functional reach test. Upon analysis, a large effect size was observed (Hedge's $g$ : 0.32), and 95\% CI (-0.22 to 0.86$) \mathrm{cm}$ was reported in the positive domain, demonstrating a beneficial effect of within dual-task training to enhance postural stability (Figure 3B). Heterogeneity tests reported negligible

\begin{tabular}{|c|c|c|c|c|c|c|c|c|}
\hline A Study name & Statistics fo & $\begin{array}{l}\text { Standard } \\
\text { error }\end{array}$ & Variance & $\begin{array}{l}\text { Lower } \\
\text { limit }\end{array}$ & $\begin{array}{l}\text { Upper } \\
\text { limit }\end{array}$ & $Z$-value & $P$-value & Hedges's $\mathrm{g}$ and $95 \% \mathrm{Cl}$ \\
\hline A Buragadda et al $(2012)^{61} \mathrm{FP}$ & 1.449 & 0.402 & 0.161 & 0.662 & 2.236 & 3.609 & 0.000 & \\
\hline Silsupadol et al $(2009)^{35} \mathrm{FP}$ & 1.375 & 0.532 & 0.283 & 0.333 & 2.417 & 2.587 & 0.010 & \\
\hline Buragadda et al $(2012)^{61} \mathrm{VP}$ & 2.402 & 0.472 & 0.222 & 1.478 & 3.327 & 5.094 & 0.000 & \\
\hline Silsupadol et al $(2009)^{35} \mathrm{VP}$ & 1.161 & 0.583 & 0.340 & 0.018 & 2.304 & 1.990 & 0.047 & \\
\hline & 1.634 & 0.241 & 0.058 & 1.161 & 2.107 & 6.773 & 0.000 & \\
\hline \multicolumn{9}{|l|}{$\mathbf{B}$} \\
\hline \multirow[t]{2}{*}{ Kim et al $(2013)^{62}$} & $\begin{array}{l}0.001 \\
0.634\end{array}$ & $\begin{array}{l}0.394 \\
0.390\end{array}$ & $\begin{array}{l}0.155 \\
0.152\end{array}$ & $\begin{array}{l}-0.772 \\
-0.130\end{array}$ & $\begin{array}{l}0.774 \\
1.398\end{array}$ & $\begin{array}{l}0.003 \\
1.626\end{array}$ & $\begin{array}{l}0.998 \\
0.104\end{array}$ & \\
\hline & 0.321 & 0.277 & 0.077 & -0.222 & 0.864 & 1.158 & 0.247 & \\
\hline \multicolumn{9}{|l|}{ 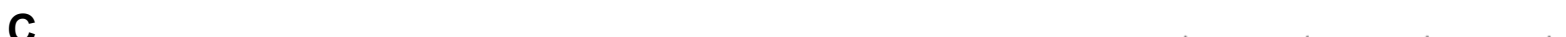 } \\
\hline \multirow[t]{2}{*}{ Negahban et al $(2011)^{65}$} & 0.001 & 0.290 & 0.084 & -0.567 & 0.569 & 0.003 & 0.998 & \\
\hline & -0.344 & 0.202 & 0.041 & -0.740 & 0.051 & -1.706 & 0.088 & \\
\hline \multicolumn{9}{|l|}{ D } \\
\hline Holmes et al $(2010)^{94}$ & -1.382 & 0.442 & 0.195 & -2.247 & -0.516 & -3.128 & 0.002 & \\
\hline \multirow[t]{2}{*}{ Melzer et al $(2001)^{80}$} & -1.029 & 0.331 & 0.109 & -1.677 & -0.381 & -3.112 & 0.002 & \\
\hline & -1.155 & 0.265 & 0.070 & -1.674 & -0.637 & -4.365 & 0.000 & \\
\hline \multicolumn{9}{|l|}{ 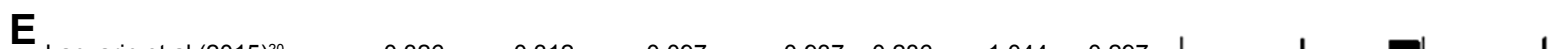 } \\
\hline Lanzarin et al $(2015)^{20}$ & -0.326 & 0.312 & 0.097 & -0.937 & 0.286 & -1.044 & 0.297 & \\
\hline \multirow[t]{2}{*}{ Resch et al $(2011)^{17}$} & 0.287 & 0.312 & 0.097 & -0.324 & 0.898 & 0.922 & 0.357 & \\
\hline & -0.019 & 0.221 & 0.049 & -0.451 & 0.413 & -0.085 & 0.932 & \\
\hline
\end{tabular}

Figure 3 Forest plot illustrating individual studies evaluating the effects of (A) dual-task training with fixed (FP) and variable (VP) priority in elderly participants, (B) dual-task training in elderly participants affected from stroke, $(\mathbf{C})$ dual-task in postural stability of participants affected from multiple sclerosis, (D) dual-task in postural stability of elderly participants, (E) dual-task in postural stability of young participants.

Notes: Adjusted effect sizes; Hedge's g (boxes), and $95 \% \mathrm{Cl}$ (whiskers) are presented, demonstrating repositioning errors for individual studies. Diamond represents pooled effect sizes and $95 \% \mathrm{Cl}$. A negative mean difference indicates a favorable outcome for control groups; a positive mean difference indicates a favorable outcome for experimental groups.

Abbreviation: $\mathrm{Cl}$, confidence interval. 
heterogeneity $\left(I^{2}: 23.2 \%, P=0.24\right)$. The studies according to the PEDro methodological scale computed an average score of 4.8 , indicating the average quality of the studies to be fair.

\section{Neurological impairments}

Eight studies evaluating the effects of dual-task performance on postural stability among participants affected by neurological disorders, such as cerebellar disorder, Parkinson's disease, ${ }^{22,92-94}$ and multiple sclerosis, ${ }^{21,65,66,91}$ were included in the review. Significant enhancements in postural stability were reported in one good ${ }^{65}$ and one fair-quality study. ${ }^{94}$ Additionally, five fair-quality studies reported a significant reduction in postural stability among individuals affected by Parkinson's disease, ${ }^{22,93,94}$ multiple sclerosis,${ }^{66}$ and degenerative cerebellar disorder. ${ }^{91}$ One good-quality study reported a reduction in postural stability (not significant) among participants affected by Parkinson's disease. ${ }^{92}$ Five studies evaluated the comparative effects between healthy participants and participants affected by neurological disorders, ${ }^{66,91,92,94}$ but one study evaluated the comparison between participants affected by mild and moderate multiple sclerosis. ${ }^{21}$ Also, two studies evaluated the inclusion of stable and unstable surfaces for maintaining postural stability while performing a dual task. ${ }^{65,91}$

A random-effect meta-analysis was conducted across one category, for evaluation of the effects of dual task on multiple sclerosis. ${ }^{21,65}$ Even though the two included studies conducted the tests using different dual tasks, the methodology and included participants were similar at baseline. The meta-analysis comprehensively demonstrated the differential effects of complexity of dual tasks on postural stability, ie, where on the one hand silent backward counting task improved the postural stability of the participants with multiple sclerosis, on the other hand incorporating word list generation task, incorporated by Boes et al, ${ }^{21}$ adversely impacted postural stability. Upon analysis, a large effect size was observed (Hedge's g: -0.34 ) and $95 \% \mathrm{CI}(-0.74$ to 0.05$)$ $\mathrm{cm}$ was reported marginally in the negative domain, demonstrating a differential effect of dual-task complexity on the postural stability of participants with multiple sclerosis (Figure 3C). Heterogeneity tests reported considerable heterogeneity ( $I: 63.6 \%, P=0.08)$. The increased heterogeneity could be attributed to the differential complexity of dual tasks within the studies, which according to Vuillerme and Vincent ${ }^{97}$ might affect the outcome of the primary task. According to PEDro methodological scale, the studies overall scored an average of 4.8, indicating the quality of the studies to be fair.

\section{Young and elderly}

Twenty-six studies evaluated the effects of dual-task performance on postural stability among young, elderly, young/elderly, and participants with/without history of falls. ${ }^{16,17,20,67-80,82-89}$ Eleven fair-quality studies evaluated the effects of dual tasks on young participants. 16,17,20,67,72, $75,77,81,82,85,89$ Four fair-quality studies reported significant enhancements in postural stability, ${ }^{16,17,77,85}$ whereas seven fair-quality studies reported significant reduction in postural stability. $20,67,72,75,81,82,89$

Two fair-quality studies evaluated the effects of dual tasks on elderly participants. ${ }^{70,74}$ Both the studies reported a significant reduction in postural stability post dual-task intervention.

Thirteen fair-quality studies compared the effects of dual

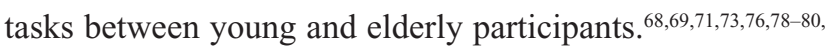
83,84,86-88 Four studies included a comparison between elderly participants with/without history of falls. ${ }^{69,70,83,84}$ Three studies reported significant enhancements in postural stability among both young and elderly participants. ${ }^{68,76,86}$ Eight studies reported significant reductions in postural stability of elderly participants as compared to younger participants where enhancements in postural stability were observed. ${ }^{21,73,79,80,83,84,87,88}$ Two studies reported reduced postural stability (nonsignificant) among elderly participants; however, enhancements were observed in younger counterparts. Similarly, significantly reduced posturasl stability was reported for participants with prior history of fall as compared to their healthy counterparts. ${ }^{69,70,83,84}$ A randomeffect meta-analysis was conducted across two categories for evaluation of the effects of dual task on healthy young participants. The two studies analyzed the postural stability using sensory orientation test; however, differential dual tasks were incorporated in the review. ${ }^{17,20}$ The methodology and included participants were similar at baseline. The meta-analysis comprehensively demonstrated the differential effects of complexity of dual tasks on postural stability, ie, where on the one hand auditory switch task improved the postural stability of the participants, ${ }^{17}$ on the other hand, incorporating a complex mental arithmetic task adversely impacted postural stability among young participants. Upon analysis, a trivial effect size was observed (Hedge's $g$ : - 0.02) and $95 \% \mathrm{CI}(-0.45$ to 0.41$) \%$ was reported marginally in the negative domain, demonstrating a differential effect of dual-task complexity on the postural stability of young participants (Figure 3E). Heterogeneity tests reported considerable heterogeneity $\left(I^{2}: 48.2 \%, P=0.93\right)$, which could possibly be related to the differential complexity of the dual 
tasks incorporated within the studies. A second random-effect meta-analysis was conducted to evaluate the effects of dual task on elderly participants. The two studies analyzed the postural stability using length of center of pressure path; however, different dual tasks were included in the studies. Despite the complexity, these cognitive tasks demonstrated detrimental effects of dual tasks on postural stability of elderly participants. The methodology and included participants were similar at baseline. Upon analysis, a large effect size was observed (Hedge's $g$ : -1.15 ) and 95\% CI $(-1.67$ to -0.63$) \mathrm{cm}$ was reported considerably in the negative domain, demonstrating a negative effect of dual-task complexity on the postural stability of elderly participants (Figure 3). Heterogeneity tests reported negligible heterogeneity $\left(I^{2}: 0 \%, P>0.01\right)$. The studies according to the PEDro methodological scale computed an average score of 4.2, indicating the average quality of the studies to be fair.

\section{Discussion}

This systematic review aimed to extend our understanding of the effects of dual tasks and dual-task training on static and dynamic postural stability among healthy and fall-prone population groups. Beneficial effects of dual-task training on postural stability of participants especially with poor balance capabilities were observed in this review. A PEDro $1 \mathrm{~b}$ level of evidence and random-effect meta-analysis demonstrated the beneficial effects of dual-task training for enhancing postural stability among fall-prone population groups.

The review observed beneficial effects of dual-task training in studies analyzing patients affected from subacute $^{34}$ and chronic stroke. ${ }^{48,62}$ The studies reported patients affected from stroke to possess considerable impairments in their cognitive-motor domain. Because of this, altered weight distribution has been reported in stroke patients while maintaining static and dynamic postures. ${ }^{98}$ However, An et $\mathrm{al}^{48}$ and Kim et $\mathrm{al}^{62}$ performed a dual-task training regime (30-min session, three times a week for 8 weeks) and reported beneficial effects on postural stability even for conditions with visual restriction and/or unstable base when presented with dual tasks. These enhancements were also evident in the meta-analysis where enhancements in functional reach test (Hedge's $g$ : 0.32 ) and $95 \% \mathrm{CI}(-0.22$ to 0.86$) \mathrm{cm}$ were observed. The authors justified the beneficial effects by suggesting prevention of tipping effect. ${ }^{48}$ This review, however, believes training could have possibly allowed skill acquisition for the cognitive and motor task while making the use of reactive forces, which in turn has been shown to reduce active muscular contraction. ${ }^{99}$ This can possibly aid in reduction of muscular coactivation and muscle guardingrelated decrements in postural stability. ${ }^{6}$ A meta-analysis conducted by Wang et $\mathrm{al}^{51}$ also reported similar beneficial effects among stroke patients; 95\% CI (0.54-5.21).

Furthermore, Silsupadol et $\mathrm{al}^{35}$ and Buragadda et $\mathrm{al}^{61}$ in their respective studies demonstrated a differential aspect of dual-task training with variable task prioritization. Metaanalysis revealed a beneficial effect of 95\% CI (1.19-2.63) in variable priority as compared to $95 \% \mathrm{CI}(0.79-2.05)$ in the fixed priority condition. The authors in their respective studies also reported enhancements in cognitive task performance, rate of learning, and ability to maintain skill level during follow-up period. Silsupadol et $\mathrm{al}^{35}$ interestingly affirmed the enhancements obtained because of dual-task training toward the task integration hypothesis, which states better development of task coordination skills following practicing with two tasks together. Likewise, Kramer et $\mathrm{a}^{100}$ in their study reported similar benefits during variable priority training and suggested that participants under variable priority conditions can learn to coordinate between two tasks during training. The authors speculated that the processing demand needed to perform a task was less when the attention was divided between two tasks. Moreover, the authors also reported a training effect during a 3-month follow-up within the variable priority condition as compared to fixed priority condition. ${ }^{35}$ According to Shigematsu et al, ${ }^{101}$ the training phase with a motor component enhances neural functioning and reduces response latency by effectively recruiting postural muscles resulting in improved sensory information processing. The review also identified radiological evidence by Erickson et al, ${ }^{102}$ which suggested enhanced cerebral hemodynamics in dorsolateral prefrontal cortex within the dual-task training group, and associated this effect with improved performance. In addition, certain centers of the brain associated with dual-task processing showed less activation posttraining, implying reduced processing demands posttraining. ${ }^{102}$ Some studies have also implied this training maneuver to act as a cognitive therapy for patients with attentional deficits and cognitive impairments. ${ }^{34,52}$ Furthermore, this review identified dual-task training regimes to also allow benefits in cognitive performance. ${ }^{38,52}$ According to Hiyamizu et $\mathrm{al}^{36}$ and Wollesen and Voelcker-Rehage, ${ }^{38}$ enhancements in cognitive performance might lead toward smoothening of cognitive activities while maintaining static and dynamic postures, resulting in preventing falls. The authors of the present review also believe that the enhancements in stability and dual-task performance are highly associated with the findings of Wolpert et $\mathrm{al}^{103}$ and Masters and Maxwell. ${ }^{9}$ In the present study, the initial phase of learning is suggested to be 
more cognitively driven as compared to the later stages of learning, which in a dual-task training setting might get more fluent and independent. Our results are in line with previously conducted systematic reviews, where dual-task training has been reported to enhance postural stability and cognitive performance..$^{38,49,50,52}$ However, this review is the first to reveal beneficial effects of dual-task training in a meta-analysis and a level of evidence analysis.

This review observed detrimental effects of dual tasks on postural stability for the participants with higher predisposition to fall. For instance, complexity-associated reduction in postural stability was reported for patients affected with multiple sclerosis ${ }^{21}$ and Parkinson's disease. ${ }^{93}$ Researchers suggest incorporation of two underlying theories for this detrimental effect, ie, bottleneck and capacity model theories. ${ }^{21,104}$ Boes et $\mathrm{al}^{21}$ suggested that since the patients with neurological impairments such as multiple sclerosis, stroke, Parkinson's disease, and elderly participants have cognitive deficits, it is possible that the neurological capacity for these patients would be even less in terms of the aforementioned models. However, the findings of systematic reviews conducted by Learmonth et $\mathrm{al}^{31}$ and Wajda and Sosnoff ${ }^{30}$ concluded minimal effects of cognitive-motor interferences on postural stability for patients with multiple sclerosis and their healthy counterparts. The meta-analysis conducted by Learmonth et $\mathrm{al}^{31}$ revealed a small effect size of -0.11 .

Furthermore, explaining the factors causing additional balance discrepancies in patients with parkinsonism, Bohnen et $\mathrm{al}^{105}$ and Andrade et $\mathrm{al}^{22}$ discussed that the dopaminergic and cholinergic pathways play a significant role in stabilizing the control of posture. These pathways play an important role in affecting the prioritization of posture and dual tasks within the central sharing model. The review conducted by Dirnberger and Jahanshahi ${ }^{106}$ supported these results and pointed out the considerable reduction in dopaminergic neuron in posterior putamen, anterior striatum, limbic nuclei, and neocortical extensions. ${ }^{107,108}$ As mentioned earlier, the basal ganglia-cortical network is involved in managing the "conscious" aspects of postural stability. ${ }^{6}$ Therefore, it might play an extensive role in causing considerable cognitive-motor interferences to reduce dual-task performance and postural stability and even promote posture "second" strategy. ${ }^{109}$ Marchese et al ${ }^{92}$ added that the dual task, ie, calculation, motor sequence of thumb opposition task, might have caused the Parkinson's patients to shift their attention, further leading to disturbed conscious control and reduced stability. Interestingly, one study analyzing patients with parkinsonism revealed beneficial effects of dual-task application. The authors from the study suggested that the patients constrained their posture for directing attention toward the dual task, which ironically also enhanced their posture. However, the authors of the review argue that factors of complexity within a dual task have played a role for enhancing stability, ie, reduced anterior posterior sway during nonspeech conditions.

Brauer et $\mathrm{al}^{69,70}$ and Shumway-Cook et $\mathrm{l}^{84}$ reported postural stability and its recovery to be poorer among participants with prior history of fall as compared to their healthy counterparts, while performing a dual task (verbal reaction to auditory tone task and sentence completion with visual perception tasks). Radiological evidence by Herath et al ${ }^{110}$ and Szameitat et $\mathrm{al}^{111}$ reported the involvement of cortical areas along inferior frontal sulcus, middle frontal gyrus, and the intraparietal sulcus while performing auditory and visual reaction dual tasks. Therefore, suggesting that superimposing a dual task over already weak reorganized cortical structures may impart more stress and adversely impact postural stability. ${ }^{14}$ The findings of the present review are in line with recent review studies, ${ }^{6,26}$ where poor postural stability was also observed in fall-prone population groups as compared to their healthy younger counterparts.

Interestingly, the review found differential effects of dual tasks in studies evaluating healthy young participants and participants with balance deficits. For instance, researchers such as Vuillerme et al, ${ }^{89}$ Ramenzoni et al, ${ }^{82}$ Pellecchia, ${ }^{64}$ and Lanzarin et $\mathrm{al}^{20}$ reported detrimental effects of dual tasks on young participants; on the other hand Donker et al, ${ }^{16}$ Bergamin et al, ${ }^{68}$ Huxhold et al, ${ }^{76}$ Mak et al, ${ }^{78}$ Resch et al, ${ }^{17}$ and Hwang et $\mathrm{al}^{77}$ reported beneficial effects even among fallprone elderly participants. In addition, beneficial effects of the dual-task application were also observed in participants with multiple sclerosis ${ }^{65}$ and Parkinson's disease. ${ }^{94}$ Conventionally, according to published reports fall-prone population groups experience poor postural stability under the influence of higher information processing constraints. However, this review observed these differential results and suggests an inverse correlation between the complexity of the dual tasks and the postural stability. Researchers suggest that according to the Yerkes-Dodson law a U-shaped relation between cognitive demand and postural sway might reflect the level of arousal associated with dual cognitive task demand, ${ }^{76}$ thereby suggesting an increase in postural sway with added complexity in a cognitive task.

Jacobi et $\mathrm{al}^{91}$ analyzed the postural stability of ataxic and healthy controls using a verbal working memory task. The authors reported less center of pressure sway with reduced 
dual-task complexity for the ataxic group during a sensory orientation test. According to the authors, the involvement of cerebellum in both cognitive and motor tasks can result in increased interference, ${ }^{112}$ thereby affecting dual-task and postural performance. Also, the role of cerebellum has been reported especially during the performance of dual tasks while maintaining executive control including working memory, language, and visuospatial information. ${ }^{113}$ Radiological evidence also demonstrates increased BOLD (blood oxygen level dependent) response in the cerebellar vermis and anterior lobe while simultaneous performance of cognitive-motor tasks. ${ }^{114}$ This review also observed articulation as a major factor for complexity in terms of a dual task, yielding differential effects upon postural stability. Bensoussan et al, ${ }^{115}$ Marchese et al, ${ }^{92}$ and Yardley et al, ${ }^{116}$ for instance, reported detrimental effects of aloud verbal, arithmetic tasks on postural stability. On the contrary, Negahban et $\mathrm{al}^{65}$ and Lanzarin et $\mathrm{al}^{20}$ reported beneficial effects of nonverbal tasks on postural stability of fall-prone participants. Literature analysis revealed research studies identifying commonly used dual tasks such as verbal recital, n-back, and counting backward to be considered as more cognitively driven. ${ }^{117}$ This review also observed the studies to ignore the verbal and hearing component incorporated in a dual-task paradigm. A functional magnetic resonance imaging analysis by Behroozmand et $\mathrm{al}^{118}$ revealed the involvement of bilateral superior temporal gyrus, Heschl's gyrus, precentral gyrus, supplementary motor area, Rolandic operculum, postcentral gyrus, putamen insula, and right inferior frontal gyrus during speech production. ${ }^{119}$ Moreover, the authors mentioned that speech production is also followed by a feedback error detection system in the sensory cortex that again activates the motor areas for speech adjustments, therefore suggesting the auditory feedback as an additional factor for increasing complexity in a dual-task setting.

Yardley et al $^{116}$ speculated the interaction between muscular control of speech-associated respiration and posture to cause perturbation in posture. The authors compared complex articulated, mental tasks while analyzing postural stability and reported beneficial effects on stability in the absence of articulation. This present review also suggests that the reinvolvement of higher motor centers during speech production in a dual task might possibly result in central interference, which might impact the person's dual task and stability performance. This review also adds to the existing knowledge that dualtask paradigms involving only a mental component, such as mental arithmetic task, might also include a motor component. As mentioned earlier, hearing also incorporates activation of cortical structures, precisely bilateral superior temporal gyrus, and Heschl's gyrus. ${ }^{118}$ The phase of instructions might activate this cortical pathway and can add to the certain amount of complexity in the dual-task scenario, which although trivial might result in considerable adverse effects in fall-prone population groups. This review did not find any study that analyzed the effects of dual-task posture in the absence of auditory information, ie, via noise canceling headphones, white noise; therefore possibly explaining the reduction in stability for studies employing nonverbal dual tasks..$^{20,67}$

In summary, a systematic review was conducted across five online academic search databases: Scopus, PEDro, MEDLINE, EMBASE, and SportDiscus. A total of 1,284 articles were incorporated in our initial search, which later on implementing our inclusion criteria were reduced to 42 (Figure 1). The meta-analysis conducted on studies suggested beneficial effects of dual-task training with variable priority for enhancing postural stability, especially among elderly participants. Moreover, an inverse relation was observed between the complexity of dual task and postural stability. This review also observed an articulation component within a dual task to be a component of added complexity, which further might enhance cognitive-motor interference in fall-prone population groups. This study also reveals detrimental effects of complex dual tasks among population groups with a higher predisposition to fall, as compared to their healthy counterparts.

\section{Strengths}

This present review is the first to analyze and compare the effects of dual-task training and dual task on postural stability. Respective authors of the included papers were contacted for additional descriptive data or information. The review conformed to PRISMA guidelines in all applicable areas. A meta-analysis and a PEDro level of evidence were included for the studies included in this present review. The data used to compute the meta-analysis were used from the descriptive statistics and not identified from figures to reduce the incidence of bias. This present review was also an effort to address the limitations pertained by previously conducted reviews. For instance, a few of the previous systematic reviews carried out the search across few academic databases. For instance, Ruffieux et $\mathrm{al}^{26}$ conducted the search across two academic databases, Boisgontier et $\mathrm{al}^{6}$ across three databases, and Agmon et $\mathrm{al}^{49}$ across four academic databases. This present review identified five widely utilized and reputed academic databases and continuously updated the data over a duration of 9 months. Additionally, few keyword search terms were identified as a possible limitation factor in the previous systematic reviews. However, during our literature 
search the authors utilized a broad variety of MeSH keyword search terms (Supplementary material), which might have increased the possibilities of including a wide array of studies. The meta-analysis carried out in this present review is the first to evaluate the effects of dual-task training on elderly participants. However, it also aimed to replicate previous findings, while addressing the increased heterogeneity.

\section{Limitations}

Several limitations persisted in the systematic review, which are to be considered while interpreting the results. The average quality of the included studies according to PEDro methodological quality scale was found to be 4.7, indicating a fair quality of the studies. A high risk of bias prevailed because of the limited number of RCTs. The restriction of search strategy limited to English language, exclusion of conference proceedings and observational studies might have resulted in omission of relevant research. Inability to retrieve descriptive statistics from the respective studies and including fewer studies in the meta-analysis was also a major limitation of this study.

This present study did not impose restrictions on the type of included dual task, in order to analyze the differential effects of complexity of dual task. Therefore, a higher chance of biasing and differential outcomes can be expected. Likewise, the systematic difference between the population group base statistics related to age, weight, gender, and disease severity led to difficulty in comparing studies. A majority of the incorporated studies had a small sample size, which generates a high possibility of a type II error. ${ }^{120}$ The conclusions derived in the review based on incorporation of dual-task training in rehabilitation protocol are based on limited research.

\section{Future directions}

Future studies should focus on combining easier, nonverbal dual tasks in training during rehabilitation. Neuroimaging studies can provide additional insights for mechanisms involved during execution of nonverbal dual tasks. The review also suggests training fall-prone population groups to prioritize balance, ie, posture "first" in complex fall-prone environments; for instance escalators, narrow alleyways. ${ }^{121}$ Likewise, nonverbal tasks utilized during activity of daily living can be analyzed in dual-task training regimes. Together, real-life implications can be drawn from these studies.

\section{Acknowledgments}

The publication of this article was funded by the Open Access fund of Leibniz Universität Hannover. The authors would like to thank Dr Matthew W Driller, Prof Dr Rich SW Masters for their constructive comments. The coauthor expresses sincere gratitude toward Education New Zealand and the University of Waikato for awarding research scholarships.

\section{Disclosure}

The authors report no conflicts of interest in this work.

\section{References}

1. Wikstrom EA, Tillman MD, Smith AN, Borsa PA. A new force-plate technology measure of dynamic postural stability: the dynamic postural stability index. J Athl Train. 2005;40(4):305-309.

2. Ghai S, Driller M, Ghai I. Effects of joint stabilizers on proprioception and stability: a systematic review and meta-analysis. Phys Ther Sport. In press 2016.

3. Goble DJ, Coxon JP, Wenderoth N, Van Impe A, Swinnen SP. Proprioceptive sensibility in the elderly: degeneration, functional consequences and plastic-adaptive processes. Neurosci Biobehav Rev. 2009; 33(3):271-278.

4. Vaugoyeau M, Viel S, Amblard B, Azulay J, Assaiante C. Proprioceptive contribution of postural control as assessed from very slow oscillations of the support in healthy humans. Gait Posture. 2008;27(2):294-302.

5. Raftopoulos A. Cognitive Penetrability of Perception: Attention, Action, Strategies, and Bottom-Up Constraints. New York, NY: Nova Publishers; 2005.

6. Boisgontier MP, Beets IA, Duysens J, Nieuwboer A, Krampe RT, Swinnen SP. Age-related differences in attentional cost associated with postural dual tasks: increased recruitment of generic cognitive resources in older adults. Neurosci Biobehav Rev. 2013;37(8):1824-1837.

7. Jacobs J, Horak F. Cortical control of postural responses. J Neural Transm. 2007;114(10):1339-1348.

8. Honeycutt CF, Gottschall JS, Nichols TR. Electromyographic responses from the hindlimb muscles of the decerebrate cat to horizontal support surface perturbations. J Neurophysiol. 2009;101(6):2751-2761.

9. Masters RSW, Maxwell J. The theory of reinvestment. Int Rev Sport Exer Psychol. 2008;1(2):160-183.

10. Wulf G, McNevin N, Shea CH. The automaticity of complex motor skill learning as a function of attentional focus. Q J Exp Psychol A. 2001; 54(4):1143-1154.

11. Masters RSW. Knowledge, knerves and know-how: the role of explicit versus implicit knowledge in the breakdown of a complex motor skill under pressure. Br J Psychol. 1992;83(3):343-358.

12. Schaefer S, Schellenbach M, Lindenberger U, Woollacott M. Walking in high-risk settings: do older adults still prioritize gait when distracted by a cognitive task? Exp Brain Res. 2015;233(1):79-88.

13. Seidler RD, Bernard JA, Burutolu TB, et al. Motor control and aging: links to age-related brain structural, functional, and biochemical effects. Neurosci Biobehav Rev. 2010;34(5):721-733.

14. Talelli P, Ewas A, Waddingham W, Rothwell J, Ward N. Neural correlates of age-related changes in cortical neurophysiology. Neuroimage. 2008;40(4):1772-1781.

15. Schaefer S, Jagenow D, Verrel J, Lindenberger U. The influence of cognitive load and walking speed on gait regularity in children and young adults. Gait Posture. 2015;41(1):258-262.

16. Donker SF, Roerdink M, Greven AJ, Beek PJ. Regularity of centerof-pressure trajectories depends on the amount of attention invested in postural control. Exp Brain Res. 2007;181(1):1-11.

17. Resch JE, May B, Tomporowski PD, Ferrara MS. Balance performance with a cognitive task: a continuation of the dual-task testing paradigm. J Athl Train. 2011;46(2):170.

18. Beilock SL, Carr TH. On the fragility of skilled performance: what governs choking under pressure? J Exp Psychol Gen. 2001;130(4):701-725. 
19. Ghai S, Driller MW, Masters RS. The influence of below-knee compression garments on knee-joint proprioception. Gait Posture. Epub 2016 Aug 9.

20. Lanzarin M, Parizzoto P, Libardoni TDC, Sinhorim L, Tavares GMS, Santos GM. The influence of dual-tasking on postural control in young adults. Fisioter Pesquisa. 2015;22(1):61-68.

21. Boes MK, Sosnoff JJ, Socie MJ, Sandroff BM, Pula JH, Motl RW. Postural control in multiple sclerosis: effects of disability status and dual task. J Neurol Sci. 2012;315(1):44-48.

22. Andrade LPD, Rinaldi NM, Coelho FGDM, Tanaka K, Stella F, Gobbi LTB. Dual task and postural control in Alzheimer's and Parkinson's disease. Motriz Rev Ed Fis. 2014;20(1):78-84.

23. Montero-Odasso M, Bergman H, Phillips NA, Wong CH, Sourial N, Chertkow H. Dual-tasking and gait in people with mild cognitive impairment. The effect of working memory. BMC Geriatr. 2009;9(1):41.

24. Woollacott M, Shumway-Cook A. Attention and the control of posture and gait: a review of an emerging area of research. Gait Posture. 2002;16(1):1-14.

25. Hortobágyi T, del Olmo MF, Rothwell JC. Age reduces cortical reciprocal inhibition in humans. Exp Brain Res. 2006;171(3):322-329.

26. Ruffieux J, Keller M, Lauber B, Taube W. Changes in standing and walking performance under dual-task conditions across the lifespan. Sports Med. 2015;45(12):1739-1758.

27. Fujiyama H, Hinder MR, Schmidt MW, Garry MI, Summers JJ. Age-related differences in corticospinal excitability and inhibition during coordination of upper and lower limbs. Neurobiol Aging. 2012; 33(7):e1481-e1484.

28. Fujita H, Kasubuchi K, Wakata S, Hiyamizu M, Morioka S. Role of the frontal cortex in standing postural sway tasks while dual-tasking: a functional near-infrared spectroscopy study examining working memory capacity. Biomed Res Int. 2016;2016:7053867.

29. Smith E, Cusack T, Blake C. The effect of a dual task on gait speed in community dwelling older adults: a systematic review and metaanalysis. Gait Posture. 2016;44:250-258.

30. Wajda DA, Sosnoff JJ. Cognitive-motor interference in multiple sclerosis: a systematic review of evidence, correlates, and consequences. Biomed Res Int. 2015;2015:720856.

31. Learmonth YC, Ensari I, Motl RW. Cognitive motor interference in multiple sclerosis: insights from a systematic quantitative review. Arch Phys Med Rehabil. Epub Aug 16, 2016.

32. Zanotto T, Bergamin M, Roman F, et al. Effect of exercise on dual-task and balance on elderly in multiple disease conditions. Curr Aging Sci. 2014;7(2):115-136.

33. Gobbo S, Bergamin M, Sieverdes JC, Ermolao A, Zaccaria M. Effects of exercise on dual-task ability and balance in older adults: a systematic review. Arch Gerontol Geriatr. 2014;58(2):177-187.

34. Choi JH, Kim BR, Han EY, Kim SM. The effect of dual-task training on balance and cognition in patients with subacute post-stroke. Ann Rehabil Med. 2015;39(1):81-90.

35. Silsupadol P, Shumway-Cook A, Lugade V, et al. Effects of singletask versus dual-task training on balance performance in older adults a double-blind, randomized controlled trial. Arch Phys Med Rehabil. 2009;90(3):381-387.

36. Hiyamizu M, Morioka S, Shomoto K, Shimada T. Effects of dual task balance training on dual task performance in elderly people: a randomized controlled trial. Clin Rehabil. 2012;26(1):58-67.

37. Gomez-Pinilla F, Hillman C. The influence of exercise on cognitive abilities. Compr Physiol. 2013;3(1):403-428.

38. Wollesen B, Voelcker-Rehage C. Training effects on motor-cognitive dualtask performance in older adults. Eur Rev Aging Phys Act. 2013;11(1):5.

39. Park DC, Reuter-Lorenz P. The adaptive brain: aging and neurocognitive scaffolding. Annu Rev Psychol. 2009;60:173.

40. Brown S, Bennett E. The role of practice and automaticity in temporal and nontemporal dual-task performance. Psychol Res. 2002; 66(1):80-89.

41. Müller H, Blischke K. Grundlagen der Sportpsychologie. [Basics of sports psychology]. Limpert Verlag, Wiesbaden. 2009. German.
42. Bherer L, Kramer AF, Peterson MS, Colcombe S, Erickson K, Becic E Training effects on dual-task performance: are there age-related differences in plasticity of attentional control? Psychol Aging. 2005;20(4):695.

43. Heuer H. Motor Learning as a Process of Structural Constriction and Displacement. Berlin: Springer; 1984:295-305.

44. Blischke K, Reiter C. Bewegungsautomatisierung durch DoppeltätigkeitsÜben. [Movement automation by double action practicing.]. Spectrum der Sportwissenschaften. 2002;14:8-29.

45. Blischke K. Automatisierung einer großmotorischen Kalibrierungsaufgabe durch Prozeduralisierung. [Automation of a large-scale calibration task by proceduralization]. Psychol Sport. 2001;8:19-38.

46. Blischke K, Wagner F, Zehren B, Brueckner S. Dual-task practice of temporally structured movement sequences augments integrated task processing, but not automatization. J Human Kinet. 2010; 25:5-15.

47. Bherer L, Kramer AF, Peterson MS, Colcombe S, Erickson K, Becic E. Transfer effects in task-set cost and dual-task cost after dual-task training in older and younger adults: further evidence for cognitive plasticity in attentional control in late adulthood. Exp Aging Res. 2008; 34(3):188-219.

48. An H-J, Kim J-I, Kim Y-R, et al. The effect of various dual task training methods with gait on the balance and gait of patients with chronic stroke. J Phys Ther Sci. 2014;26(8):1287-1291.

49. Agmon M, Belza B, Nguyen HQ, Logsdon RG, Kelly VE. A systematic review of interventions conducted in clinical or community settings to improve dual-task postural control in older adults. Clin Interv Aging. 2014;9:477-492

50. Fritz NE, Cheek FM, Nichols-Larsen DS. Motor-cognitive dual-task training in persons with neurologic disorders: a systematic review. J Neurol Phys Ther. 2015;39(3):142-153.

51. Wang XQ, Pi YL, Chen BL, et al. Cognitive motor interference for gait and balance in stroke: a systematic review and meta-analysis. Eur $J$ Neurol. 2015;22(3):555-e37.

52. Pichierri G, Wolf P, Murer K, de Bruin ED. Cognitive and cognitivemotor interventions affecting physical functioning: a systematic review. BMC Geriatr. 2011;11(1):1.

53. Moher D, Liberati A, Tetzlaff J, Altman DG. Preferred reporting items for systematic reviews and meta-analyses: The PRISMA statement. Ann Intern Med. 2009;151(4):264-269.

54. Steindl R, Ulmer H. Standstabilität im kindes-und jugendalter. [Stability in childhood and adolescence]. HNO. 2004;52(5):423-430.

55. Centre for Reviews and Dissemination. Systematic Reviews: CRD's Guidance for Undertaking Reviews in Health Care. Centre for Reviews and Dissemination. York: York Publishing Services Ltd; 2009.

56. Higgins JP, Green S. Cochrane Handbook for Systematic Reviews of Interventions. Version 5. Wiley Online Library; 2008. Available from: http://handbook.cochrane.org. Accessed August 3, 2016.

57. Maher CG, Sherrington C, Herbert RD, Moseley AM, Elkins M. Reliability of the PEDro scale for rating quality of randomized controlled trials. Phys Ther. 2003;83(8):713-721.

58. Teasell RW, Foley NC, Bhogal SK, Speechley MR. Evidence-Based Review of Stroke Rehabilitation. Topics in Stroke Rehabilitation. 2003;10(1):29-58.

59. Cohen J. Statistical Power Analysis for the Behavioral Sciences. 2nd ed. Hillsdale, NJ: Lawrence Erlbaum Associates; 1988.

60. Higgins JPT, Green S, editors. Cochrane Handbook for Systematic Reviews of Interventions Version 5.0.2 [updated September 2009]. The Cochrane Collaboration, 2008.

61. Buragadda S, Alyaemni A, Melam GR, Alghamdi MA. Effect of dualtask training (fixed priority-versus-variable priority) for improving balance in older adults. World Appl Sci J. 2012;20(6):884-888.

62. Kim D, Ko J, Woo Y. Effects of dual task training with visual restriction and an unstable base on the balance and attention of stroke patients. J Phys Ther Sci. 2013;25(12):1579-1582.

63. Li KZ, Roudaia E, Lussier M, Bherer L, Leroux A, McKinley P. Benefits of cognitive dual-task training on balance performance in healthy older adults. J Gerontol A Biol Sci Med Sci. 2010;65(12):1344-1352. 
64. Pellecchia GL. Dual-task training reduces impact of cognitive task on postural sway. J Mot Behav. 2005;37(3):239-246.

65. Negahban H, Mofateh R, Arastoo AA, et al. The effects of cognitive loading on balance control in patients with multiple sclerosis. Gait Posture. 2011;34(4):479-484.

66. Prosperini L, Castelli L, Sellitto G, et al. Investigating the phenomenon of "cognitive-motor interference" in multiple sclerosis by means of dual-task posturography. Gait Posture. 2015;41(3):780-785.

67. Andersson G, Hagman J, Talianzadeh R, Svedberg A, Larsen HC. Effect of cognitive load on postural control. Brain Res Bull. 2002;58(1): 135-139.

68. Bergamin $\mathrm{M}$, Gobbo $\mathrm{S}$, Zanotto $\mathrm{T}$, et al. Influence of age on postural sway during different dual-task conditions. Front Aging Neurosci. 2014;6: 271-277.

69. Brauer S, Woollacott M, Shumway-Cook A. The influence of a concurrent cognitive task on the compensatory stepping response to a perturbation in balance-impaired and healthy elders. Gait Posture. 2002;15(1):83-93.

70. Brauer SG, Woollacott M, Shumway-Cook A. The interacting effects of cognitive demand and recovery of postural stability in balanceimpaired elderly persons. J Gerontol A Biol Sci Med Sci. 2001;56(8): M489-M496.

71. Brown LA, Shumway-Cook A, Woollacott MH. Attentional demands and postural recovery: the effects of aging. J Gerontol A Biol Sci Med Sci. 1999;54(4):M165-M171.

72. Dault MC, Geurts AC, Mulder TW, Duysens J. Postural control and cognitive task performance in healthy participants while balancing on different support-surface configurations. Gait Posture. 2001;14(3):248-255.

73. Doumas M, Smolders C, Krampe RT. Task prioritization in aging: effects of sensory information on concurrent posture and memory performance. Exp Brain Res. 2008;187(2):275-281.

74. Haggerty S, Jiang L-T, Galecki A, Sienko KH. Effects of biofeedback on secondary-task response time and postural stability in older adults. Gait Posture. 2012;35(4):523-528.

75. Hunter MC, Hoffman MA. Postural control: visual and cognitive manipulations. Gait Posture. 2001;13(1):41-48.

76. Huxhold O, Li S-C, Schmiedek F, Lindenberger U. Dual-tasking postural control: aging and the effects of cognitive demand in conjunction with focus of attention. Brain Res Bull. 2006;69(3):294-305.

77. Hwang JH, Lee C-H, Chang HJ, Park D-S. Sequential analysis of postural control resource allocation during a dual task test. Ann Rehabil Med. 2013;37(3):347-354.

78. Mak L, Yeh TT, Boulet J, Cluff T, Balasubramaniam R. Interaction between delayed visual feedback and secondary cognitive tasks on postural control in older adults. Science \& Motricité. 2011;74:81-88.

79. Marsh AP, Geel SE. The effect of age on the attentional demands of postural control. Gait Posture. 2000;12(2):105-113.

80. Melzer I, Benjuya N, Kaplanski J. Age-related changes of postural control: effect of cognitive tasks. Gerontology. 2001;47(4):189-194.

81. Pellecchia GL. Postural sway increases with attentional demands of concurrent cognitive task. Gait Posture. 2003;18(1):29-34.

82. Ramenzoni VC, Riley MA, Shockley K, Chiu C-YP. Postural responses to specific types of working memory tasks. Gait Posture. 2007;25(3): 368-373.

83. Shumway-Cook A, Woollacott M. Attentional demands and postural control: the effect of sensory context. J Gerontol A Biol Sci Med Sci. 2000;55(1):M10.

84. Shumway-Cook A, Woollacott M, Kerns KA, Baldwin M. The effects of two types of cognitive tasks on postural stability in older adults with and without a history of falls. J Gerontol A Biol Sci Med Sci. 1997; 52(4):M232-M240.

85. Swan L, Otani H, Loubert PV. Reducing postural sway by manipulating the difficulty levels of a cognitive task and a balance task. Gait Posture. 2007;26(3):470-474.

86. Swan L, Otani H, Loubert PV, Sheffert SM, Dunbar GL. Improving balance by performing a secondary cognitive task. Br J Psychol. 2004; 95(1):31-40.
87. Teasdale N, Bard C, LaRue J, Fleury M. On the cognitive penetrability of posture control. Exp Aging Res. 1993;19(1):1-13.

88. Teasdale N, Simoneau M. Attentional demands for postural control: the effects of aging and sensory reintegration. Gait Posture. 2001; 14(3):203-210.

89. Vuillerme N, Isableu B, Nougier V. Attentional demands associated with the use of a light fingertip touch for postural control during quiet standing. Exp Brain Res. 2006;169(2):232-236.

90. de Morton NA. The PEDro scale is a valid measure of the methodological quality of clinical trials: a demographic study. Aust J Physiother. 2009; 55(2):129-133.

91. Jacobi H, Alfes J, Minnerop M, Konczak J, Klockgether T, Timmann D. Dual task effect on postural control in patients with degenerative cerebellar disorders. Cerebellum Ataxias. 2015;2(1):6.

92. Marchese R, Bove M, Abbruzzese G. Effect of cognitive and motor tasks on postural stability in Parkinson's disease: a posturographic study. Mov Disord. 2003;18(6):652-658.

93. Morris M, Iansek R, Smithson F, Huxham F. Postural instability in Parkinson's disease: a comparison with and without a concurrent task. Gait Posture. 2000;12(3):205-216.

94. Holmes J, Jenkins M, Johnson AM, Adams S, Spaulding S. Dual-task interference: the effects of verbal cognitive tasks on upright postural stability in Parkinson's disease. Parkinsons Dis. 2010;2010:696492.

95. Teasell R, Marshall S, Cullen N, et al. Evidence Based Review of Moderate to Severe Acquired Brain Injury. Toronto, ON: Ontario Neurotrauma Foundation; 2005.

96. Bolier L, Haverman M, Westerhof GJ, Riper H, Smit F, Bohlmeijer E. Positive psychology interventions: a meta-analysis of randomized controlled studies. BMC Public Health. 2013;13(1):119.

97. Vuillerme N, Vincent H. How performing a mental arithmetic task modify the regulation of centre of foot pressure displacements during bipedal quiet standing. Exp Brain Res. 2006;169(1):130-134.

98. Tyson SF, Hanley M, Chillala J, Selley A, Tallis RC. Balance disability after stroke. Phys Ther. 2006;86(1):30-38.

99. Vereijken B, Whiting H, Beek W. A dynamical systems approach to skill acquisition. $Q J$ Exp Psychol. 1992;45(2):323-344.

100. Kramer AF, Larish JF, Strayer DL. Training for attentional control in dual task settings: a comparison of young and old adults. $J$ Exp Psychol Appl. 1995;1(1):50.

101. Shigematsu R, Okura T, Nakagaichi M, et al. Square-stepping exercise and fall risk factors in older adults: a single-blind, randomized controlled trial. J Gerontol A Biol Sci Med Sci. 2008;63(1): 76-82.

102. Erickson KI, Colcombe SJ, Wadhwa R, et al. Training-induced functional activation changes in dual-task processing: an FMRI study. Cereb Cortex. 2007;17(1):192-204.

103. Wolpert DM, Diedrichsen J, Flanagan JR. Principles of sensorimotor learning. Nat Rev Neurosci. 2011;12(12):739-751.

104. Tombu M, Jolicœur P. All-or-none bottleneck versus capacity sharing accounts of the psychological refractory period phenomenon. Psychol Res. 2002;66(4):274-286.

105. Bohnen N, Müller M, Koeppe R, et al. History of falls in Parkinson disease is associated with reduced cholinergic activity. Neurology. 2009;73(20):1670-1676.

106. Dirnberger G, Jahanshahi M. Executive dysfunction in Parkinson's disease: a review. J Neuropsychol. 2013;7(2):193-224.

107. Kish SJ, Shannak K, Hornykiewicz O. Uneven pattern of dopamine loss in the striatum of patients with idiopathic Parkinson's disease. N Engl J Med. 1988;318(14):876-880.

108. Kalaitzakis ME, Pearce RK. The morbid anatomy of dementia in Parkinson's disease. Acta Neuropathol. 2009;118(5):587-598.

109. Yogev-Seligmann G, Hausdorff JM, Giladi N. Do we always prioritize balance when walking? Towards an integrated model of task prioritization. Mov Disord. 2012;27(6):765-770.

110. Herath P, Klingberg T, Young J, Amunts K, Roland P. Neural correlates of dual task interference can be dissociated from those of divided attention: an fMRI study. Cereb Cortex. 2001;11(9):796-805. 
111. Szameitat AJ, Schubert T, Müller K, Von Cramon DY. Localization of executive functions in dual-task performance with fMRI. $J$ Cogn Neurosci. 2002;14(8):1184-1199.

112. Schmahmann JD, Pandyat DN. The cerebrocerebellar system. Int Rev Neurobiol. 1997;41:31-60.

113. Timmann D, Daum I. Cerebellar contributions to cognitive functions: a progress report after two decades of research. Cerebellum. 2007; 6(3):159-162.

114. Wu T, Liu J, Hallett M, Zheng Z, Chan P. Cerebellum and integration of neural networks in dual-task processing. Neuroimage. 2013;65: 466-475.

115. Bensoussan L, Viton J-M, Schieppati M, et al. Changes in postural control in hemiplegic patients after stroke performing a dual task. Arch Phys Med Rehabil. 2007;88(8):1009-1015.

116. Yardley L, Gardner M, Leadbetter A, Lavie N. Effect of articulatory and mental tasks on postural control. Neuroreport. 1999;10(2):215-219.

117. Kane MJ, Conway AR, Miura TK, Colflesh GJ. Working memory, attention control, and the N-back task: a question of construct validity. J Exp Psychol Learn Mem Cogn. 2007;33(3):615.
118. Behroozmand R, Shebek R, Hansen DR, et al. Sensory-motor networks involved in speech production and motor control: an fMRI study. Neuroimage. 2015;109:418-428.

119. Parkinson AL, Flagmeier SG, Manes JL, Larson CR, Rogers B, Robin DA. Understanding the neural mechanisms involved in sensory control of voice production. Neuroimage. 2012;61(1):314-322.

120. Freiman JA, Chalmers TC, Smith H Jr, Kuebler RR. The importance of beta, the type II error and sample size in the design and interpretation of the randomized control trial: survey of 71 negative trials. $N$ Engl J Med. 1978;299(13):690-694.

121. Bloem BR, Grimbergen YA, van Dijk JG, Munneke M. The "posture second" strategy: a review of wrong priorities in Parkinson's disease. J Neurol Sci. 2006;248(1):196-204.

122. Ramsey L, Winder RJ, McVeigh JG. The effectiveness of working wrist splints in adults with rheumatoid arthritis: a mixed methods systematic review. J Rehabil Med. 2014;46(6):481-492.
Clinical Interventions in Aging

\section{Publish your work in this journal}

Clinical Interventions in Aging is an international, peer-reviewed journal focusing on evidence-based reports on the value or lack thereof of treatments intended to prevent or delay the onset of maladaptive correlates of aging in human beings. This journal is indexed on PubMed Central, MedLine,

\section{Dovepress}

CAS, Scopus and the Elsevier Bibliographic databases. The manuscript management system is completely online and includes a very quick and fair peer-review system, which is all easy to use. Visit http://www.dovepress. $\mathrm{com} /$ testimonials.php to read real quotes from published authors. 